Supporting Information

\title{
Daphneodorins A-C, anti-HIV gnidimacrin related macrocyclic daphnane orthoesters from Daphne odora
}

Kouharu Otsuki, ${ }^{a}$ Wei Li,,${ }^{\mathrm{a},}{ }^{*}$ Yoshihisa Asada, ${ }^{\mathrm{a}}$ Chin-Ho Chen, ${ }^{\mathrm{b}}$ Kuo-Hsiung Lee, ${ }^{\mathrm{c}, \mathrm{d}}$ Kazuo Koike

${ }^{a}$ Faculty of Pharmaceutical Sciences, Toho University, Miyama 2-2-1, Funabashi, Chiba 274-8510, Japan

burgical Science, Department of Surgery, Duke University Medical Center, Durham, NC, 27710, United States

${ }^{\mathrm{c}}$ Natural Products Research Laboratories, UNC Eshelman School of Pharmacy, University of North Carolina, Chapel Hill, NC, 27599, United States

${ }^{\mathrm{d} C h i n e s e}$ Medicine Research and Development Center, China Medical University and Hospital, Tiachung, 40447, Taiwan

\section{Contents}

\section{Experimental section}

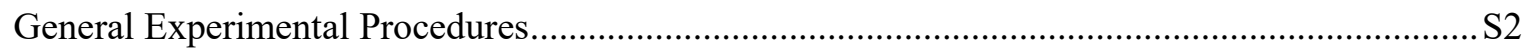

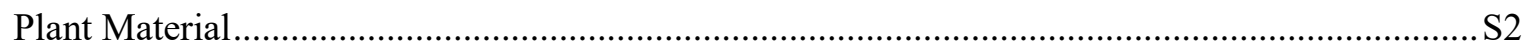

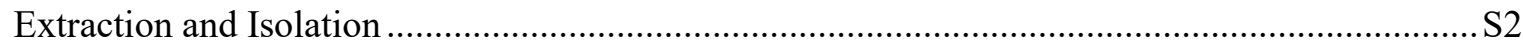

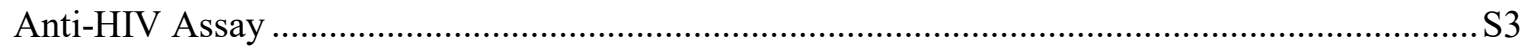

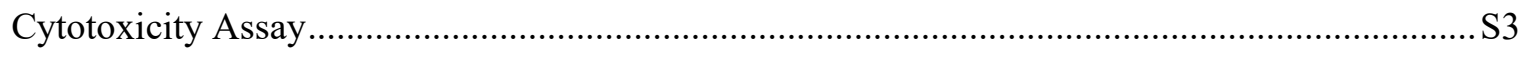

\section{Spectroscopic data}

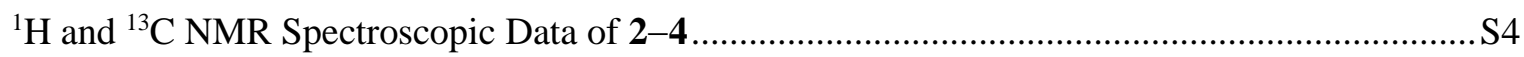

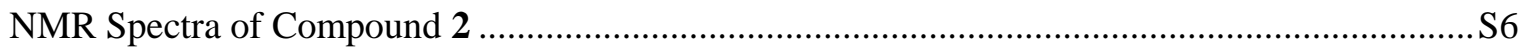

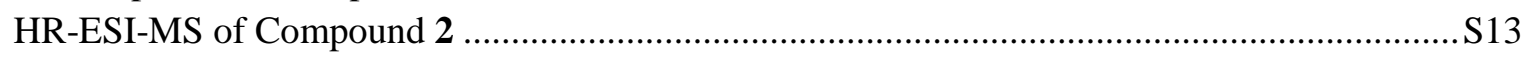

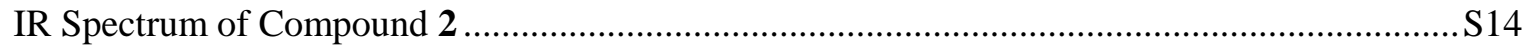

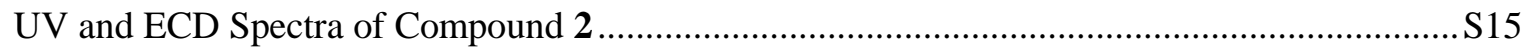

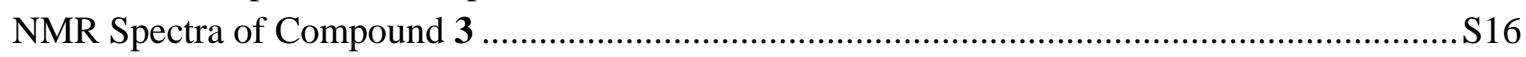

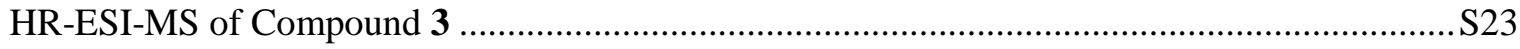

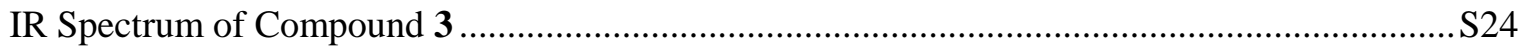

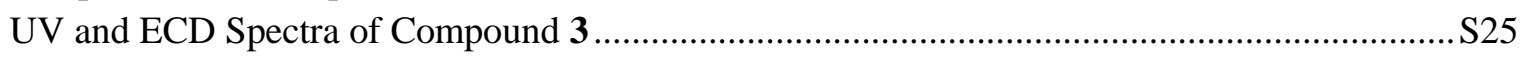

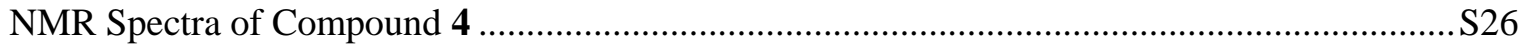

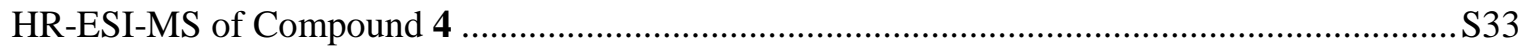

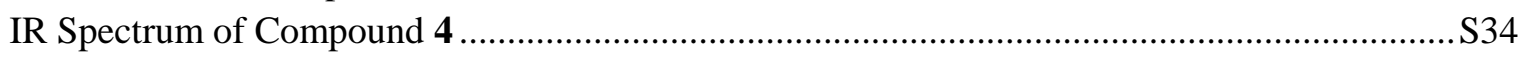

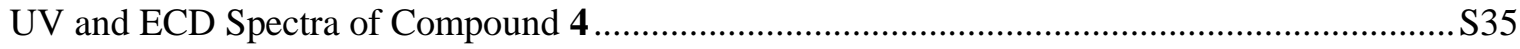




\section{EXPERIMENTAL SECTION}

\section{General Experimental Procedures}

Optical rotations were measured on a JASCO P-2200 polarimeter in a $0.5-\mathrm{dm}$ cell. The UV spectra were obtained with a Shimadzu BioSpec-mini spectrophotometer. The IR spectra were measured on a JASCO FT/IR 4100 Fourier transform infrared spectrometer using the $\mathrm{KBr}$ disk method. The NMR spectra were measured on a JEOL ECA-500 spectrometer with the deuterated solvent used as the internal reference. The ${ }^{1} \mathrm{H}$ NMR spectra were recorded at $500 \mathrm{MHz}$, and the ${ }^{13} \mathrm{C}$ NMR spectra were recorded at $125 \mathrm{MHz}$. The chemical shifts are expressed in $\delta(\mathrm{ppm})$; and were reported as s (singlet), d (doublet), $\mathrm{t}$ (triplet), dd (doublet of doublet), br (broad) and $\mathrm{m}$ (multiplet), respectively. HRTOFESIMS was conducted using a JEOL JMST100LP AccuTOF LC-plus mass spectrometer. Diaion HP-20 (Mitsubishi Chemical Corporation, Tokyo, Japan), Silica gel (Chromatorex PEI MB 100-40/75, Fuji Silysia Chemical Ltd., Aichi, Japan) and ODS (Cosmosil 75C 18 -PREP, Nacalai Tesque, Inc., Kyoto, Japan) were used for column chromatography. For preparative HPLC, a Waters 515 HPLC pump, equipped with a ERC RefractoMax520 differential refractometer detector and a Shimadzu SPD-10A UV-vis detector, was used. For reversed-phase (RP) HPLC separation, an RP-C ${ }_{18}$ silica gel column (YMC-Actus Triart C18, 150×20 $\mathrm{mm}$ ) was used at a flow rate of $8.0 \mathrm{~mL} / \mathrm{min}$. For normal-phase (NP) HPLC separation, a silica gel column (YMC-Pack SIL, $250 \times 20 \mathrm{~mm}$ ) was used at a flow rate of $5.0 \mathrm{~mL} / \mathrm{min}$.

\section{Plant Material}

The branches of Daphne odora, which cultivated in Toho University Medicinal Plant Garden, Chiba, Japan, were collected in June 2015, and identified by one of the authors, W.L. A voucher specimen (TH11) has been deposited at the Department of Pharmacognosy, Faculty of Pharmaceutical Sciences, Toho University, Japan.

\section{Extraction and Isolation}

The air-dried branches of D.odora $(950 \mathrm{~g})$ were cut into small pieces, then the dried pieces were extracted ultrasonically with $\mathrm{MeOH}(4 \mathrm{~L} \times 20 \mathrm{~min}, 5$ times), at room temperature. The methanolic extract was concentrated (226 g), suspended in $\mathrm{H}_{2} \mathrm{O}$, and then partitioned with EtOAc. The EtOAc fraction (92.4 g) was subjected to Diaion HP-20 column chromatography and eluted with a stepwise gradient of $\mathrm{MeOH}-\mathrm{H}_{2} \mathrm{O}$ (from 5:5 to 10:0, v/v), finally with acetone to afford four fractions (E1 to E4). Fraction E3 $(13.2 \mathrm{~g})$ was subjected to silica gel column chromatography and eluted with a gradient of $n$ hexane-AcOEt- $\mathrm{MeOH}-\mathrm{HCOOH}$ to afford seven fractions (1 to 6). Fraction 5 (2.80 g) was further subjected to ODS column chromatography and eluted with a gradient of $\mathrm{MeOH}-\mathrm{H}_{2} \mathrm{O}$, finally with $\mathrm{CHCl}_{3}$ to afford eight subfractions (5-1 to 5-8). Fraction 5-3 (150 mg) was separated by RP-HPLC (70\% $\mathrm{CH}_{3} \mathrm{CN}$ ) to afford eleven subfractions (5-3-1 to 5-3-11). Fraction 5-3-4 (9.3 mg) was purified by NPHPLC ( $n$-hexane-AcOEt, 1:2) to give $3(3.5 \mathrm{mg})$ and 4 (1.6 mg). Fraction 5-3-6 (7.0 mg) was purified by RP-HPLC $\left(70 \% \mathrm{CH}_{3} \mathrm{CN}\right)$ to give $2(2.0 \mathrm{mg})$. Fraction $5-4(56.2 \mathrm{mg})$ was purified by RP-HPLC (70\% $\left.\mathrm{CH}_{3} \mathrm{CN}\right)$ to give $\mathbf{1}(1.5 \mathrm{mg})$. 
Daphneodorin A (2): Colorless solid; $[\alpha]_{\mathrm{D}}^{23}+21.6$ (c 0.10, MeOH); UV (MeOH) $\lambda_{\max }(\log \varepsilon) 229$ (4.32) nm; ECD (MeOH): $[\theta]^{25}$ (nm) 1041 (210), -12614 (223), 13148 (239); IR (KBr) v $v_{\max }$ 3448, 2929, 1719, 1452, 1315, 1279, 1177, 1101, $1027 \mathrm{~cm}^{-1}$; ${ }^{1} \mathrm{H}$ and ${ }^{13} \mathrm{C}$ NMR spectroscopic data, see Table S1 and Table S2; HR-ESI-TOF-MS (positive) $\mathrm{m} / z$ 975.3769 [M+Na] ${ }^{+}$(calcd for $\mathrm{C}_{53} \mathrm{H}_{60} \mathrm{O}_{16} \mathrm{Na}$, 975.3779).

Daphneodorin B (3): Colorless solid; $[\alpha]_{\mathrm{D}}^{24}-11.0$ (c 0.10, MeOH); UV (MeOH) $\lambda_{\max }(\log \varepsilon) 229$ (4.48) nm; ECD (MeOH): $[\theta]^{25}(\mathrm{~nm})-22204$ (210), -20886 (216), -23524 (223), 34714 (240); IR (KBr) $v_{\max }$ 3446, 2963, 1719, 1452, 1317, 1284, 1262, 1099, $1027 \mathrm{~cm}^{-1} ;{ }^{1} \mathrm{H}$ and ${ }^{13} \mathrm{C}$ NMR spectroscopic data, see Table S1 and Table S2; HR-ESI-TOF-MS (positive) $\mathrm{m} / z$ 1033.3839 $[\mathrm{M}+\mathrm{Na}]^{+}$(calcd for $\mathrm{C}_{55} \mathrm{H}_{62} \mathrm{O}_{18} \mathrm{Na}$, 1033.3834).

Daphneodorin C (4): Colorless solid; $[\alpha]_{\mathrm{D}}^{24}-1.7$ (c 0.10, MeOH); UV (MeOH) $\lambda_{\max }(\log \varepsilon) 228$ (4.34) nm; ECD (MeOH): $[\theta]^{25}(\mathrm{~nm})-16003$ (210), -15210 (215), -16647 (222), 20681 (240); IR (KBr) $v_{\max }$ $3447,2928,1719,1452,1316,1284,1263,1101,1027 \mathrm{~cm}^{-1} ;{ }^{1} \mathrm{H}$ and ${ }^{13} \mathrm{C}$ NMR spectroscopic data, see Table S1 and Table S2; HR-ESI-TOF-MS (positive) $\mathrm{m} / z 1033.3843[\mathrm{M}+\mathrm{Na}]^{+}$(calcd for $\mathrm{C}_{55} \mathrm{H}_{62} \mathrm{O}_{18} \mathrm{Na}$, 1033.3834)

\section{Anti-HIV Assay}

HIV-1 NL4-3 (multiplicity of infection $=0.001$ ) was used to infect MT4 cells in the presence of various concentrations of compounds. Fresh medium containing appropriate concentrations of the compounds were added to the culture $48 \mathrm{~h}$ after infection to maintain normal cell growth. Virus replication was analyzed 4-day postinfection using p24 ELISA kits from Perkin-Elmer. The compound concentration that inhibited HIV-1 replication by $50 \%\left(\mathrm{EC}_{50}\right)$ was calculated by using the biostatistic software CalcuSyn (Biosoft).

\section{Cytotoxicity Assay}

Cytotoxicity of the compounds to MT4 cells was determined by using a cell viability kit provided by Promega. The CellTiter-Glo Luminescent Cell Viability Assay is a simple method of determining the viability of the cells in culture based on quantitation of ATP in metabolically active cells. The CellTiterGlo reagent was added to the MT4 cells that were cultured parallel to the antiviral assays. The compound concentration that decreased the cell viability by $50 \%\left(\mathrm{IC}_{50}\right)$ was calculated by using CalcuSyn (Biosoft). 
Table S1. ${ }^{1} \mathrm{H}$ and ${ }^{13} \mathrm{C}$ NMR spectroscopic data of $2-4\left(\mathrm{CDCl}_{3}\right)$ : the daphnane part.

\begin{tabular}{|c|c|c|c|c|c|c|}
\hline \multirow[b]{2}{*}{ No. } & \multicolumn{2}{|l|}{2} & \multicolumn{2}{|l|}{3} & \multicolumn{2}{|l|}{4} \\
\hline & $\delta_{\mathrm{H}}(J$ in $\mathrm{Hz})$ & $\delta_{\mathrm{C}}$ & $\delta_{\mathrm{H}}(J$ in $\mathrm{Hz})$ & $\delta_{\mathrm{C}}$ & $\delta_{\mathrm{H}}(J$ in $\mathrm{Hz})$ & $\delta_{\mathrm{C}}$ \\
\hline 1 & $3.03(1 \mathrm{H}, \mathrm{t}, 12.6)$ & 49.2 & $3.00(1 \mathrm{H}, \mathrm{t}, 12.6)$ & 49.3 & $2.74(1 \mathrm{H}, \mathrm{t}, 12.6)$ & 48.2 \\
\hline 2 & $1.78(1 \mathrm{H})^{\mathrm{a}}$ & 37.3 & $1.76(1 \mathrm{H})^{\mathrm{a}}$ & 37.3 & $1.62(1 \mathrm{H})^{\mathrm{a}}$ & 37.7 \\
\hline 3 & $4.88(1 \mathrm{H}, \mathrm{d}, 5.2)$ & 82.4 & $4.89(1 \mathrm{H}, \mathrm{d}, 4.5)$ & 82.3 & $3.79(1 \mathrm{H})^{\mathrm{a}}$ & 79.2 \\
\hline 4 & & 79.4 & & 79.5 & & 78.3 \\
\hline 5 & $4.04(1 \mathrm{H}, \mathrm{d}, 2.5)$ & 73.7 & $4.07(1 \mathrm{H}, \mathrm{brs})$ & 73.6 & $3.77(1 \mathrm{H}, \mathrm{brs})$ & 71.1 \\
\hline 6 & & 60.7 & & 60.7 & & 60.0 \\
\hline 7 & 3.35 (1H, brs) & 63.5 & 3.38 (1H, brs) & 63.3 & 3.37 (1H, brs) & 63.2 \\
\hline 8 & $3.00(1 \mathrm{H}, \mathrm{d}, 2.8)$ & 36.7 & $3.00(1 \mathrm{H}, \mathrm{d}, 2.6)$ & 36.7 & $3.03(1 \mathrm{H}, \mathrm{d}, 2.6)$ & 36.6 \\
\hline 9 & & 81.6 & & 81.6 & & 81.5 \\
\hline 10 & $2.95(1 \mathrm{H}, \mathrm{d}, 12.6)$ & 48.3 & $3.05(1 \mathrm{H}, \mathrm{d}, 12.6)$ & 48.1 & $2.93(1 \mathrm{H}, \mathrm{d}, 12.6)$ & 48.2 \\
\hline 11 & $2.65(1 \mathrm{H}, \mathrm{ddd}, 10.6,7.7,2.7)$ & 41.1 & $2.66(1 \mathrm{H}, \mathrm{ddd}, 10.5,7.8,2.9)$ & 41.1 & $2.64(1 \mathrm{H}, \mathrm{ddd}, 10.5,7.7,2.6)$ & 40.8 \\
\hline \multirow[t]{2}{*}{12} & $1.87(1 \mathrm{H}, \mathrm{dd}, 14.6,7.7) \alpha$ & 29.1 & $1.88(1 \mathrm{H}, \mathrm{dd}, 14.6,7.8) \alpha$ & 29.2 & $1.97(1 \mathrm{H})^{\mathrm{a}} \alpha$ & 29.2 \\
\hline & $2.24(1 \mathrm{H}, \mathrm{d}, 14.6) \beta$ & & $2.23(1 \mathrm{H}, \mathrm{d}, 14.6) \beta$ & & $2.24(1 \mathrm{H}, \mathrm{d}, 14.3) \beta$ & \\
\hline 13 & & 84.6 & & 84.6 & & 84.5 \\
\hline 14 & $4.37(1 \mathrm{H}, \mathrm{d}, 2.8)$ & 81.4 & $4.37(1 \mathrm{H}, \mathrm{d}, 2.6)$ & 81.4 & $4.40(1 \mathrm{H}, \mathrm{d}, 2.6)$ & 81.2 \\
\hline 15 & & 145.3 & & 145.4 & & 145.4 \\
\hline \multirow[t]{2}{*}{16} & $4.92(1 \mathrm{H}, \mathrm{s})$ & 111.9 & $4.92(1 \mathrm{H}, \mathrm{brs})$ & 111.8 & $4.95(1 \mathrm{H}, \mathrm{t}, 1.5)$ & 111.9 \\
\hline & $5.14(1 \mathrm{H}, \mathrm{s})$ & & $5.14(1 \mathrm{H}, \mathrm{brs})$ & & $5.18(1 \mathrm{H}, \mathrm{brs})$ & \\
\hline 17 & $1.79(3 \mathrm{H}, \mathrm{s})$ & 19.0 & $1.79(3 \mathrm{H}, \mathrm{brs})$ & 19.0 & $1.83(3 \mathrm{H}, \mathrm{brs})$ & 19.0 \\
\hline \multirow[t]{2}{*}{18} & $4.07(1 \mathrm{H}, \mathrm{t}, 10.6)$ & 66.7 & $4.07(1 \mathrm{H}, \mathrm{t}, 10.5)$ & 66.7 & $4.09(1 \mathrm{H}, \mathrm{t}, 10.5)$ & 67.5 \\
\hline & $4.93(1 \mathrm{H})^{\mathrm{a}}$ & & $4.90(1 \mathrm{H}, \mathrm{dd}, 10.5,2.9)$ & & $4.69(1 \mathrm{H}, \mathrm{dd}, 10.5,2.6)$ & \\
\hline 19 & $1.19(3 \mathrm{H}, \mathrm{d}, 6.9)$ & 14.6 & $1.16(3 \mathrm{H}, \mathrm{d}, 6.6)$ & 14.6 & $1.15(3 \mathrm{H}, \mathrm{d}, 6.9)$ & 14.4 \\
\hline \multirow[t]{2}{*}{20} & $3.81(2 \mathrm{H}, \mathrm{m})$ & 65.9 & $3.83(1 \mathrm{H}, \mathrm{d}, 12.8)$ & 65.7 & $4.26(1 \mathrm{H}, \mathrm{d}, 12.2)$ & 67.5 \\
\hline & & & $3.85(1 \mathrm{H}, \mathrm{d}, 12.8)$ & & $4.91(1 \mathrm{H}, \mathrm{d}, 12.2)$ & \\
\hline
\end{tabular}

averlapping resonances. 
Table S2. ${ }^{1} \mathrm{H}$ and ${ }^{13} \mathrm{C}$ NMR spectroscopic data of $2-4\left(\mathrm{CDCl}_{3}\right)$ : the macrocyclic ring part and acyl moieties.

\begin{tabular}{|c|c|c|c|c|c|c|}
\hline \multirow[b]{2}{*}{ No. } & \multicolumn{2}{|l|}{2} & \multicolumn{2}{|l|}{3} & \multicolumn{2}{|l|}{4} \\
\hline & $\delta_{\mathrm{H}}(J$ in $\mathrm{Hz})$ & $\delta_{\mathrm{C}}$ & $\delta_{\mathrm{H}}(J$ in $\mathrm{Hz})$ & $\delta_{\mathrm{C}}$ & $\delta_{\mathrm{H}}(J$ in $\mathrm{Hz})$ & $\delta_{\mathrm{C}}$ \\
\hline $1^{\prime}$ & & 118.2 & & 118.2 & & 118.2 \\
\hline $2^{\prime}$ & $3.89(1 \mathrm{H}, \mathrm{dd}, 7.5,3.5) \alpha$ & 70.4 & $4.38(1 \mathrm{H})^{\mathrm{a}} \alpha$ & 69.8 & $4.39(1 \mathrm{H})^{\mathrm{a}} \alpha$ & 69.5 \\
\hline $3^{\prime}$ & $1.64,1.68($ each $1 \mathrm{H}, \mathrm{m})$ & 28.6 & $1.67(2 \mathrm{H}, \mathrm{m})$ & 26.5 & $1.67(2 \mathrm{H}, \mathrm{m})$ & 26.5 \\
\hline \multirow[t]{2}{*}{$4^{\prime}$} & $1.48,1.68($ each $1 \mathrm{H}, \mathrm{m})$ & 21.6 & $1.73(1 \mathrm{H}, \mathrm{m}) \alpha$ & 29.7 & $1.77(1 \mathrm{H}, \mathrm{m}) \alpha$ & 29.3 \\
\hline & & & $1.88(1 \mathrm{H})^{\mathrm{a}} \beta$ & & $1.85(1 \mathrm{H}, \mathrm{m}) \beta$ & \\
\hline \multirow[t]{2}{*}{$5^{\prime}$} & $1.82(1 \mathrm{H}, \mathrm{m}) \alpha$ & 25.1 & $5.45(1 \mathrm{H}, \mathrm{d}, 10.0) \alpha$ & 68.6 & $5.38(1 \mathrm{H}, \mathrm{dd}, 10.5,1.9) \alpha$ & 68.8 \\
\hline & $2.07(1 \mathrm{H}, \mathrm{m}) \beta$ & & & & & \\
\hline $6^{\prime}$ & $5.38(1 \mathrm{H}, \mathrm{d}, 10.3) \beta$ & 72.2 & $5.33(1 \mathrm{H}$, brs $) \beta$ & 69.4 & $5.33(1 \mathrm{H}, \mathrm{brs}) \beta$ & 69.4 \\
\hline $7^{\prime}$ & $5.63(1 \mathrm{H}, \mathrm{dd}, 10.7,5.1) \beta$ & 74.8 & $5.61(1 \mathrm{H}$, brd, 7.1$) \beta$ & 73.4 & $5.58(1 \mathrm{H}, \mathrm{dd}, 10.6,4.3) \beta$ & 73.6 \\
\hline \multirow[t]{2}{*}{$8^{\prime}$} & $1.66(1 \mathrm{H}, \mathrm{m}) \beta$ & 29.0 & $1.55(1 \mathrm{H}, \mathrm{m}) \beta$ & 28.9 & $1.53(1 \mathrm{H}, \mathrm{m}) \beta$ & 29.0 \\
\hline & $1.76(1 \mathrm{H}, \mathrm{m}) \alpha$ & & $1.97(1 \mathrm{H}, \mathrm{m}) \alpha$ & & $1.96(1 \mathrm{H}, \mathrm{m}) \alpha$ & \\
\hline $9^{\prime}$ & $2.43(1 \mathrm{H}, \mathrm{m}) \beta$ & 28.2 & $2.39(1 \mathrm{H}, \mathrm{m}) \beta$ & 28.3 & $2.31(1 \mathrm{H}, \mathrm{m}) \beta$ & 28.6 \\
\hline \multirow[t]{2}{*}{$10^{\prime}$} & $1.46(3 \mathrm{H}, \mathrm{d}, 7.4)$ & 18.3 & $1.38(3 \mathrm{H}$, brd, 5.5$)$ & 18.3 & $1.27(3 \mathrm{H}, \mathrm{d}, 7.2)$ & 18.5 \\
\hline & $3-\mathrm{Bz}$ & & $3-\mathrm{Bz}$ & & $20-\mathrm{Bz}$ & \\
\hline $\mathrm{Bz}-\mathrm{CO}$ & & 168.4 & & 168.2 & & 166.5 \\
\hline $\mathrm{Bz}-1$ & & 129.2 & & 129.5 & & 129.7 \\
\hline $\mathrm{Bz}-2,6$ & $8.21(2 \mathrm{H}, \mathrm{dd}, 8.3,1.2)$ & 130.3 & $8.20(2 \mathrm{H}, \mathrm{dd}, 8.0,1.4)$ & 130.3 & $8.08(2 \mathrm{H}, \mathrm{dd}, 8.0,1.4)$ & 129.9 \\
\hline $\mathrm{Bz}-3,5$ & $7.47(2 \mathrm{H}, \mathrm{t}, 8.3)$ & 128.6 & $7.46(2 \mathrm{H}, \mathrm{t}, 8.0)$ & 128.5 & $7.43(2 \mathrm{H}, \mathrm{t}, 8.0)$ & 128.4 \\
\hline \multirow[t]{2}{*}{ Bz-4 } & $7.60(1 \mathrm{H}, \mathrm{tt}, 8.3,1.2)$ & 133.7 & $7.59(1 \mathrm{H}, \mathrm{tt}, 8.0,1.4)$ & 133.6 & $7.53(1 \mathrm{H}, \mathrm{tt}, 8.0,1.4)$ & 133.1 \\
\hline & 6'-Bz & & $5^{\prime}-\mathrm{Bz}$ & & $5^{\prime}-\mathrm{Bz}$ & \\
\hline $\mathrm{Bz}-\mathrm{CO}$ & & 166.7 & & 165.5 & & 165.4 \\
\hline $\mathrm{Bz}-1$ & & 130.1 & & 130.1 & & 130.3 \\
\hline $\mathrm{Bz}-2,6$ & $7.93(2 \mathrm{H}, \mathrm{dd}, 8.3,1.1)$ & 129.7 & $7.90(2 \mathrm{H}, \mathrm{dd}, 7.8,1.1)$ & 129.8 & $7.89(2 \mathrm{H}, \mathrm{dd}, 8.3,1.2)$ & 129.8 \\
\hline $\mathrm{Bz}-3,5$ & $7.35(2 \mathrm{H}, \mathrm{t}, 8.3)$ & 128.3 & $7.23(2 \mathrm{H}, \mathrm{t}, 7.8)$ & 128.1 & $7.21(2 \mathrm{H}, \mathrm{t}, 8.3)$ & 128.1 \\
\hline $\mathrm{Bz}-4$ & $7.49(1 \mathrm{H}, \mathrm{tt}, 8.3,1.1)$ & 133.0 & $7.40(1 \mathrm{H}, \mathrm{t}, 7.8)$ & 132.8 & $7.39(1 \mathrm{H}, \mathrm{tt}, 8.3,1.2)$ & 132.7 \\
\hline 7'-Bz-CO & & 165.8 & & 166.0 & & 166.1 \\
\hline 7'-Bz-1 & & 130.5 & & 129.4 & & 129.5 \\
\hline 7'-Bz-2,6 & $8.07(2 \mathrm{H}, \mathrm{dd}, 8.3,1.2)$ & 129.7 & $7.69(2 \mathrm{H}$, brd, 6.6$)$ & 129.6 & $7.70(2 \mathrm{H}$, brd, 7.5$)$ & 129.6 \\
\hline 7'-Bz-3,5 & $7.47(2 \mathrm{H}, \mathrm{t}, 8.3)$ & 128.4 & $6.89(2 \mathrm{H}, \mathrm{m})$ & 127.8 & $6.89(2 \mathrm{H}, \mathrm{m})$ & 127.8 \\
\hline 7'-Bz-4 & $7.58(1 \mathrm{H}, \mathrm{tt}, 8.3,1.2)$ & 133.0 & $7.23(1 \mathrm{H}, \mathrm{t}, 6.6)$ & 132.6 & $7.21(1 \mathrm{H}, \mathrm{t}, 7.5)$ & 132.6 \\
\hline $18-\mathrm{Ac}-\mathrm{CO}$ & & 170.8 & & 170.8 & & 171.8 \\
\hline $18-A c-1$ & $2.10(3 \mathrm{H}, \mathrm{s})$ & 21.2 & $2.10(3 \mathrm{H}, \mathrm{s})$ & 21.2 & $2.09(3 \mathrm{H}, \mathrm{s})$ & 21.2 \\
\hline 6'-Ac-CO & & & & 171.0 & & 171.0 \\
\hline 6'-Ac-1 & & & $2.18(3 \mathrm{H}, \mathrm{brs})$ & 21.0 & $2.17(3 \mathrm{H}, \mathrm{s})$ & 21.0 \\
\hline 2'-OH & $2.09(1 \mathrm{H}, \mathrm{d}, 3.5)$ & & & & & \\
\hline
\end{tabular}




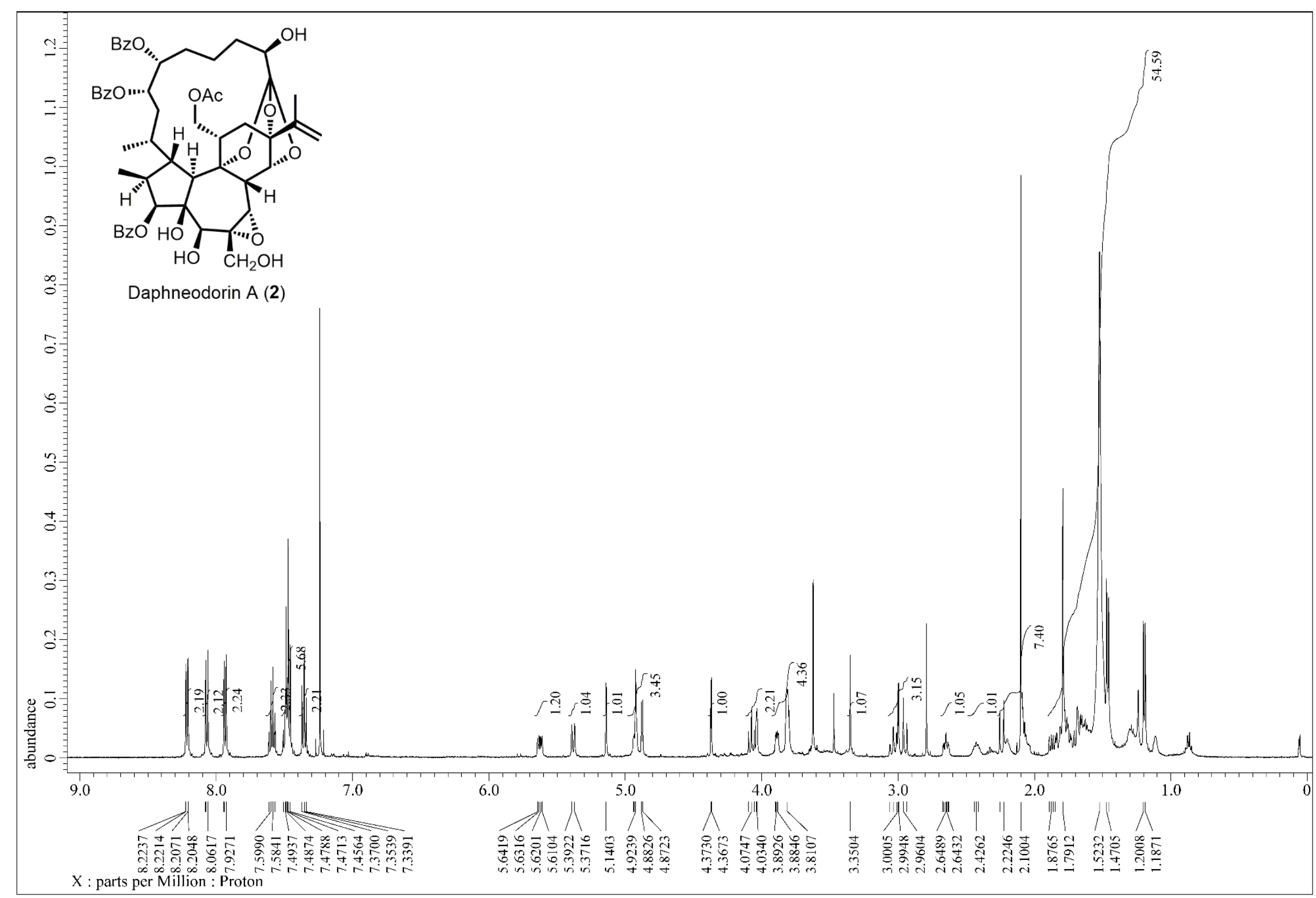

Figure S1. The ${ }^{1} \mathrm{H}-\mathrm{NMR}$ Spectrum of Compound 2. 


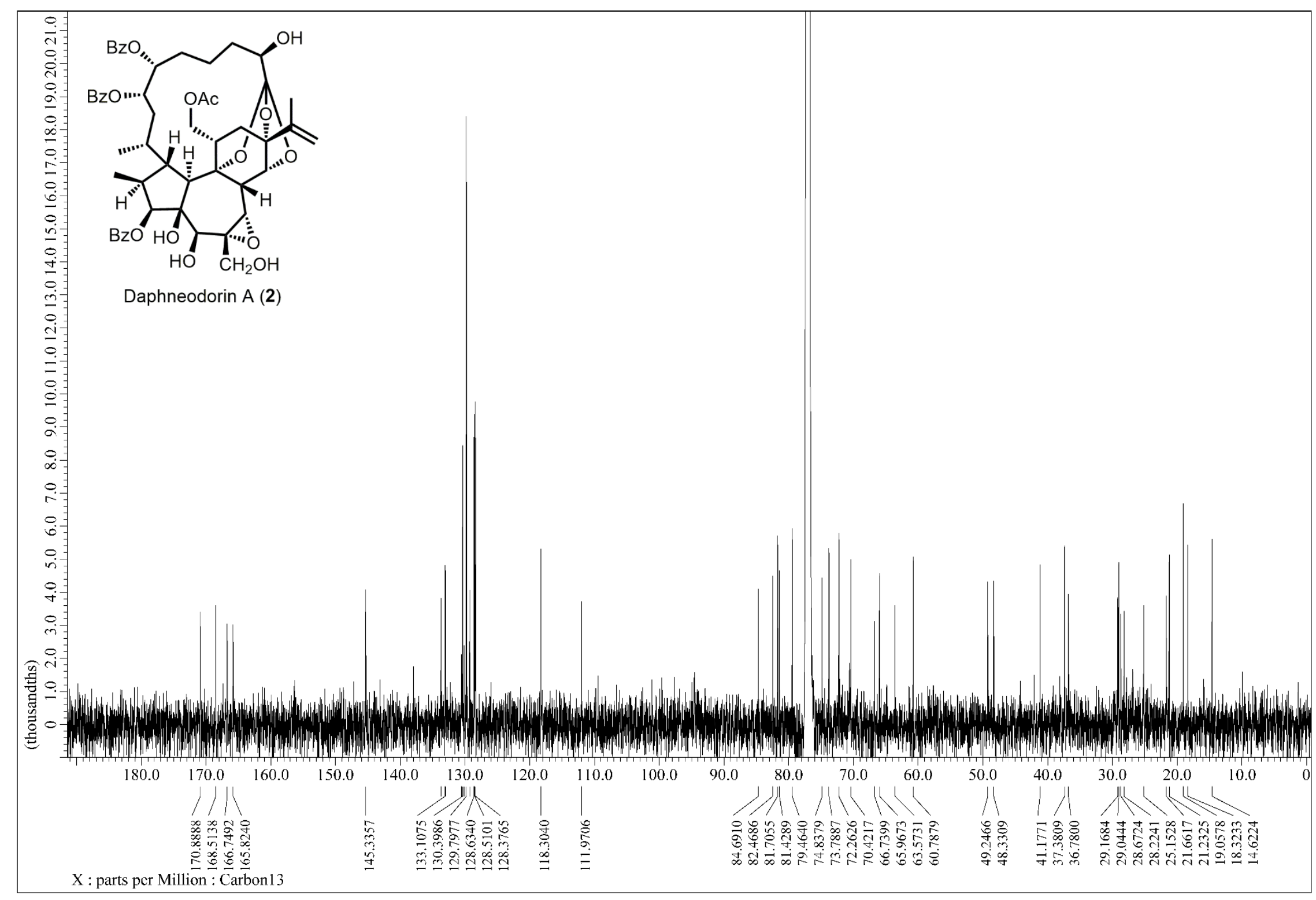

Figure S2. The ${ }^{13} \mathrm{C}-\mathrm{NMR}$ Spectrum of Compound 2. 


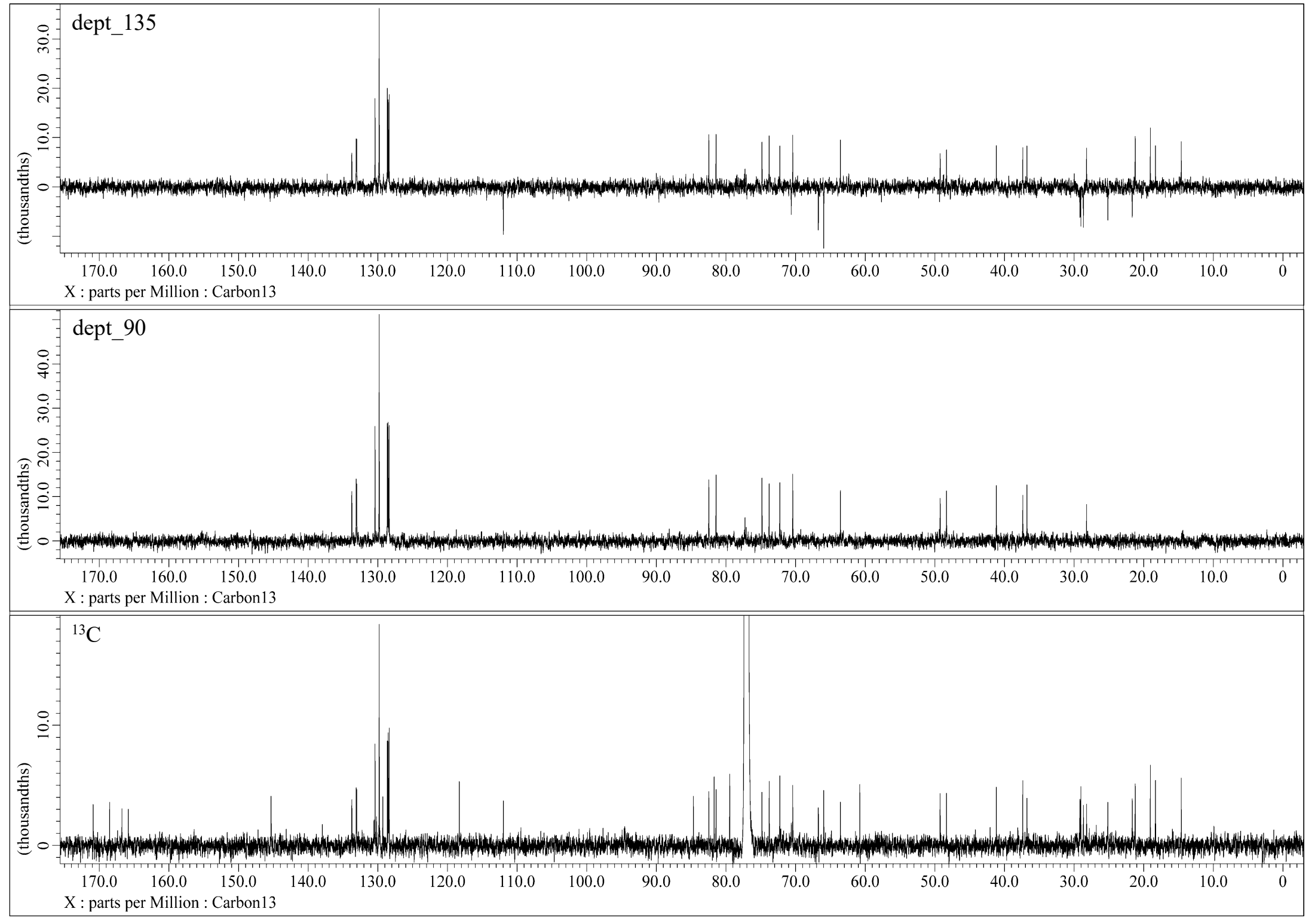

Figure S3. The DEPT Spectrum of Compound 2. 


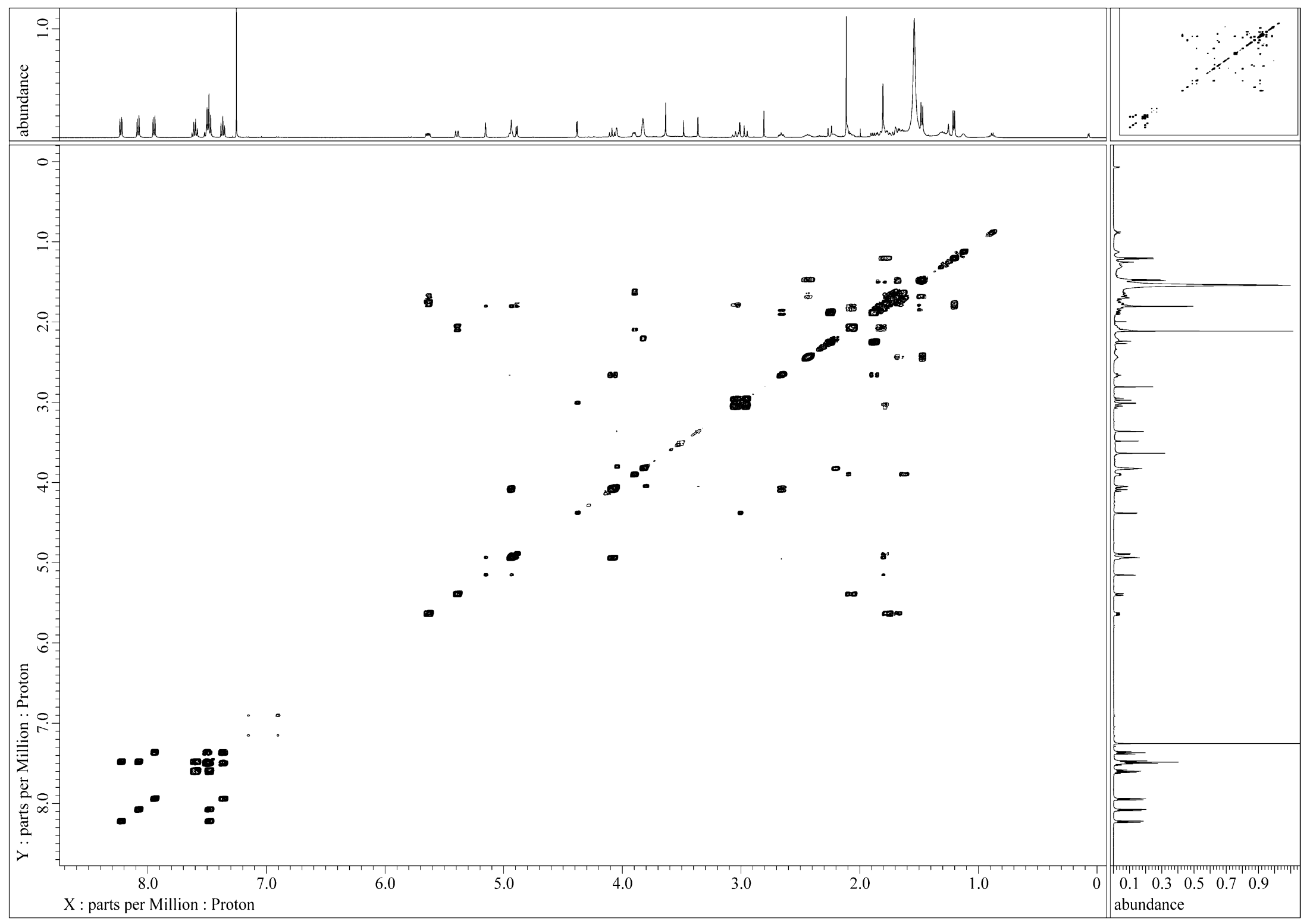

Figure S4. The DQF-COSY Spectrum of Compound 2. 


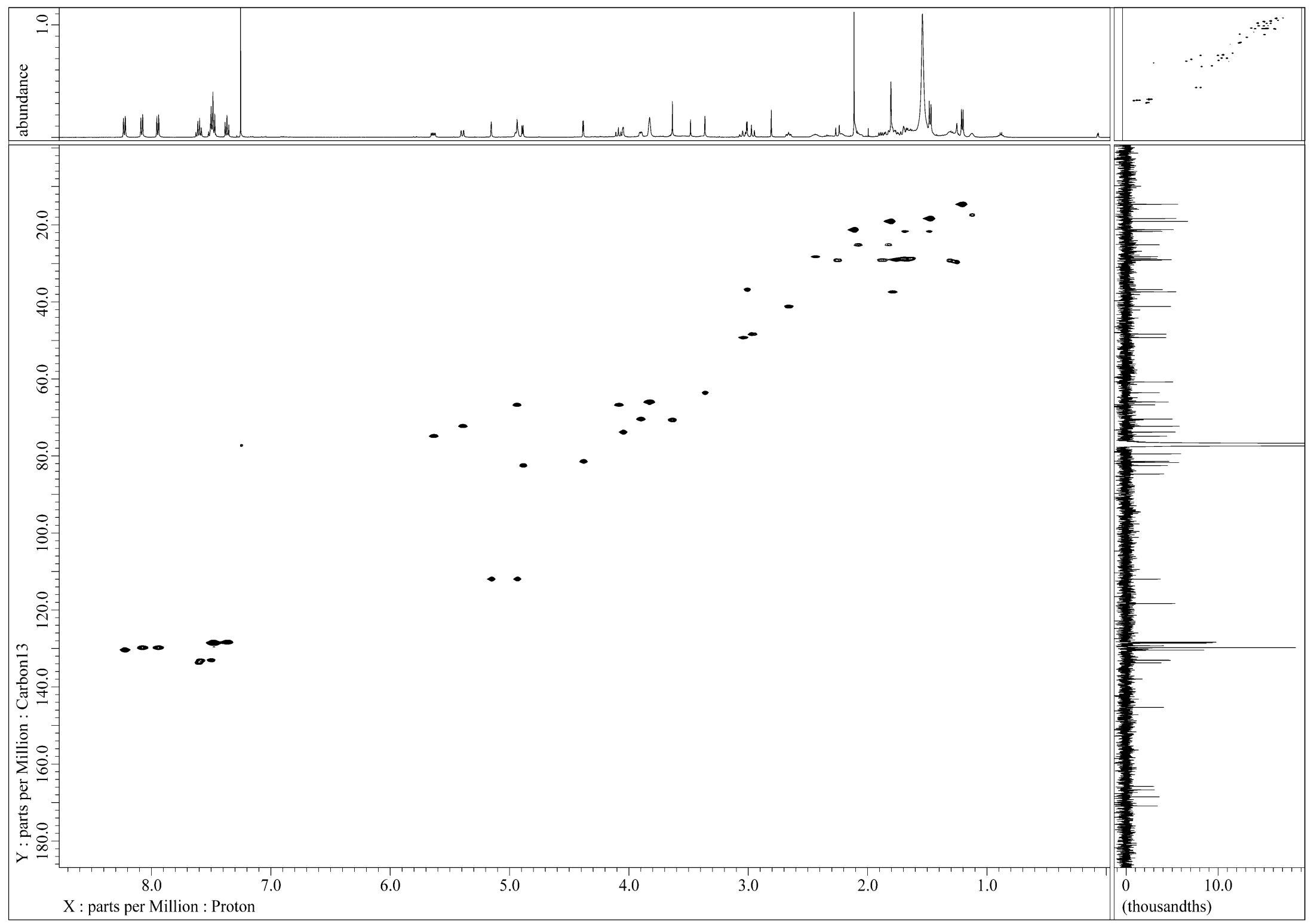

Figure S5. The HSQC Spectrum of Compound 2. 


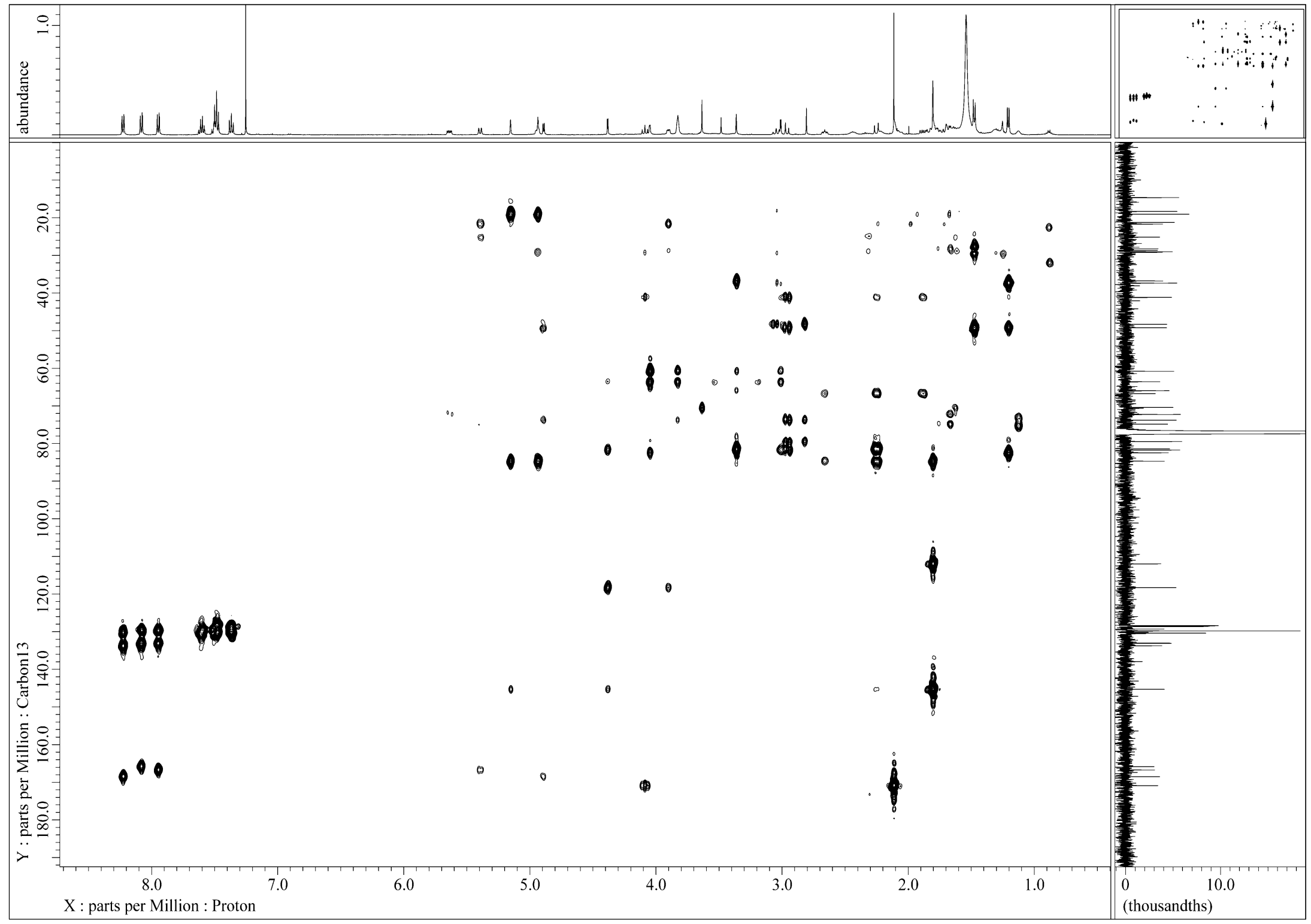

Figure S6. The HMBC Spectrum of Compound 2. 


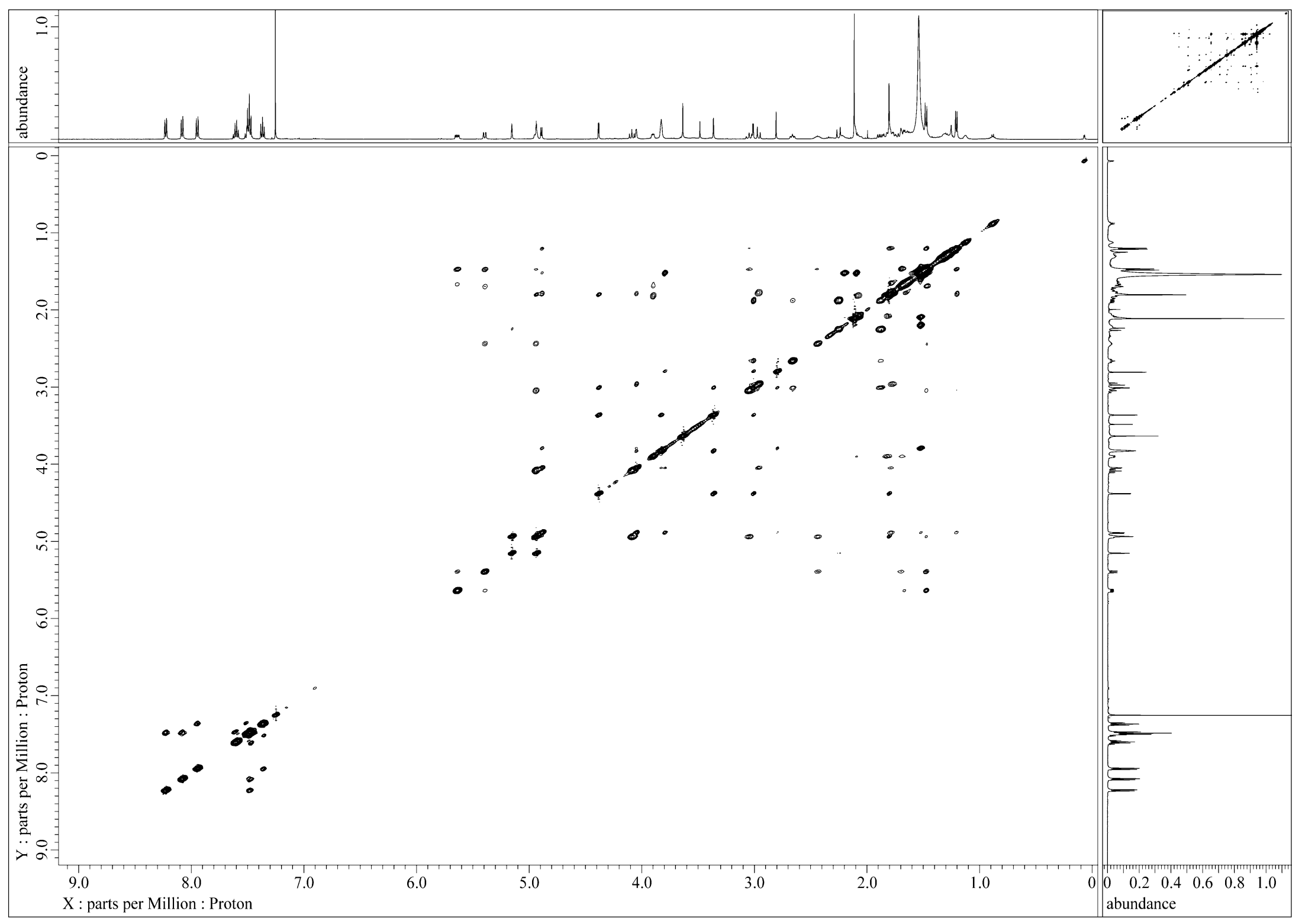

Figure S7. The NOESY Spectrum of Compound 2. 
データ:DOSO-K 181117

試料名:

説明:

イオン化モード:ESI+

処理履歴: $\mathrm{m} / \mathrm{z}$ 軸決定[ピーク検出[重心, 30 ,面積];ベース補正[5.0\%];平滑化[3]];ベース補正[5.0\%];平均(MS[1] 0.39..0.45)

電荷数: 1

元素: ${ }^{12} \mathrm{C}: 0 . .100,{ }^{1} \mathrm{H}: 0 . .200,{ }^{23} \mathrm{Na}: 1 . .1,{ }^{16} \mathrm{O}: 0 . .20$

\begin{tabular}{|c|l|r|r|r|r|r|r|}
\hline 質量 & 強度 & 相対強度 & 計算質量 & $\begin{array}{c}\text { 質量差 } \\
\mathrm{mmu}\end{array}$ & $\begin{array}{c}\text { 質量差 } \\
\mathrm{ppm}\end{array}$ & 推定組成式 & 不飽和数 \\
\hline \hline 975.37687 & 36727.18 & 100.00 & 975.37790 & -1.04 & -1.06 & ${ }^{12} \mathrm{C}_{53}{ }^{1} \mathrm{H}_{60}{ }^{23} \mathrm{Na}_{1}{ }^{16} \mathrm{O}_{16}$ & 23.5 \\
\hline
\end{tabular}

相対強度

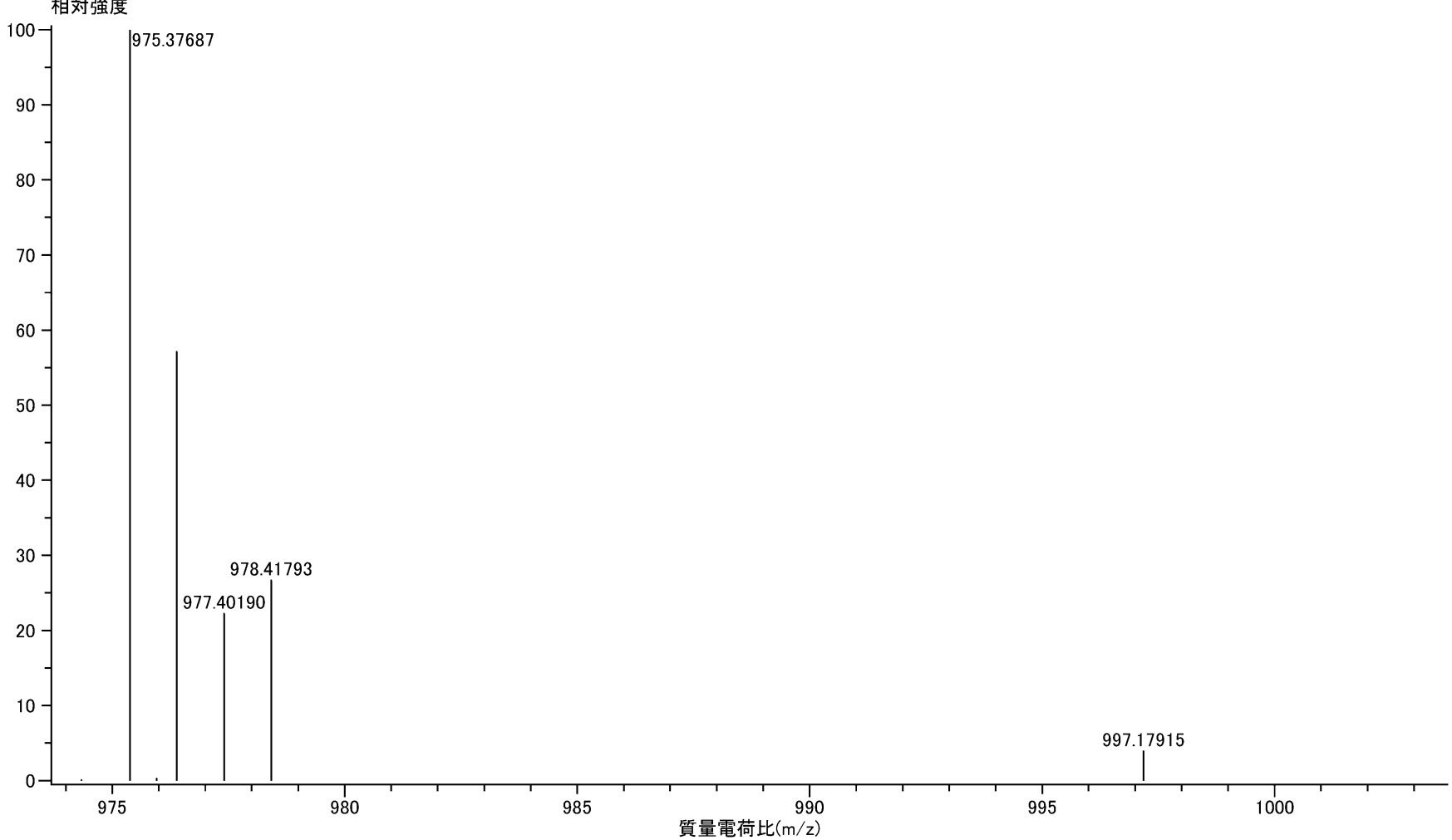

Figure S8. The HR-ESI-MS Spectrum of Compound 2.
測定日時: $2018 / 11 / 17$ 12:21:14 測定者: Administrator

質量校正データ: $190627+$

作成日時:2019/06/27 13:19:12

作成者: Administrator

不飽和数: -1.5 .. 30.0 (端数: 両方) 


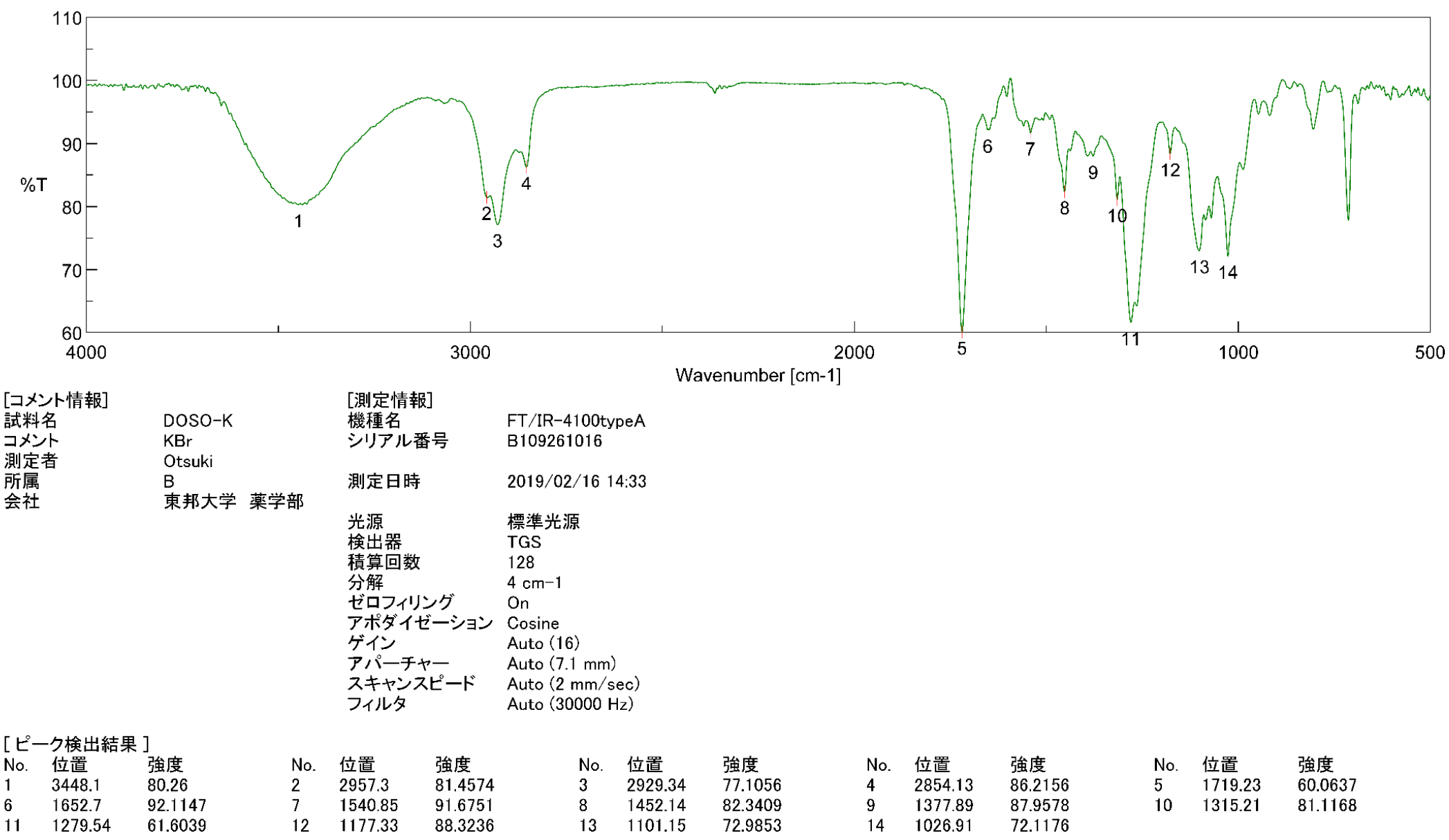

Figure S9. The IR Spectrum of Compound 2. 


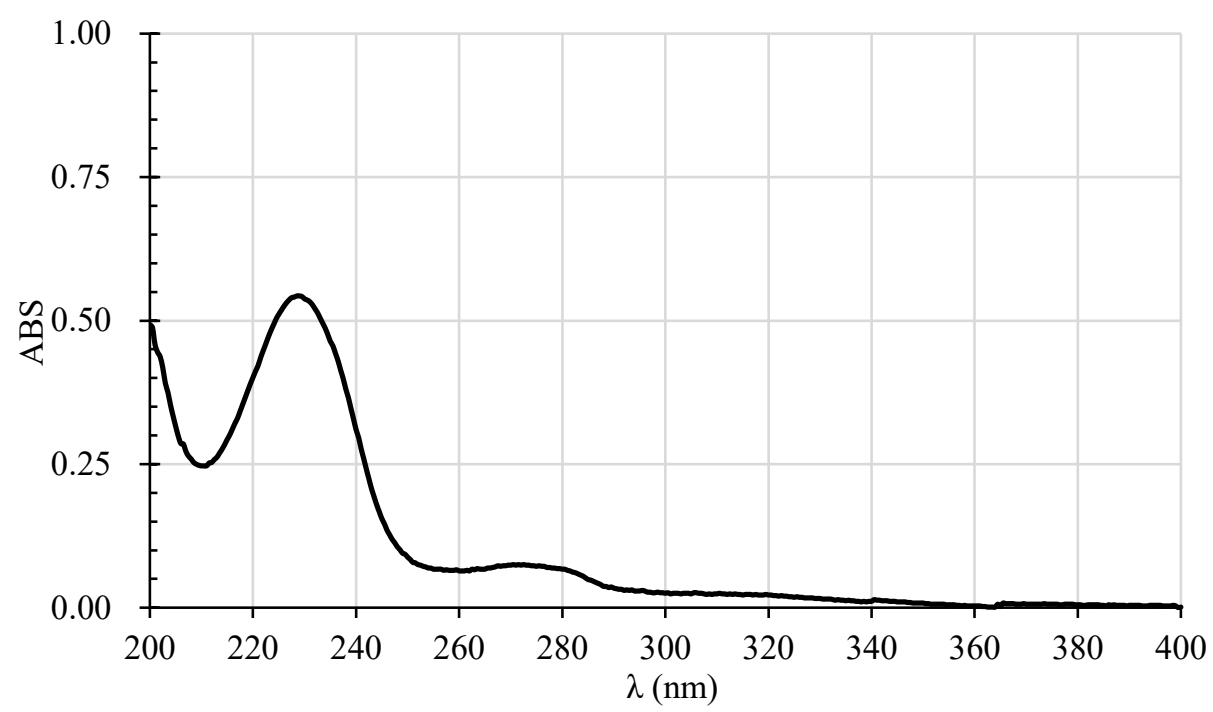

Figure S10. The UV Spectrum of Compound 2.

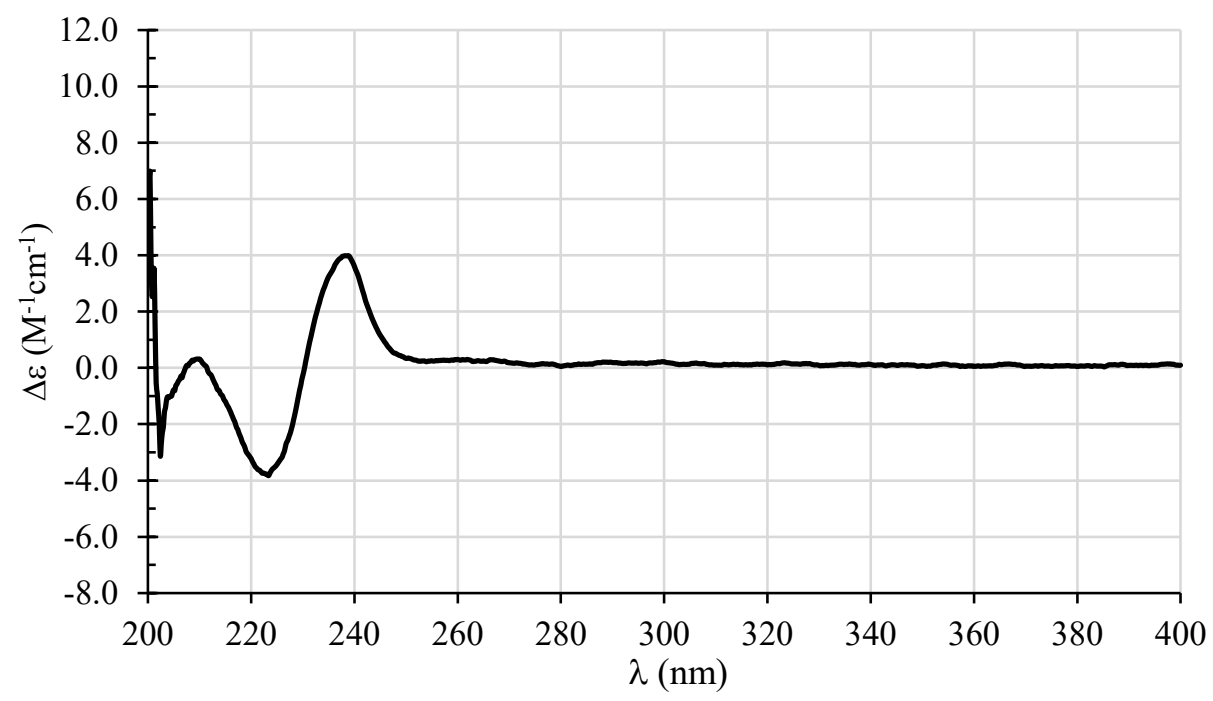

Figure S11. The ECD Spectrum of Compound 2. 


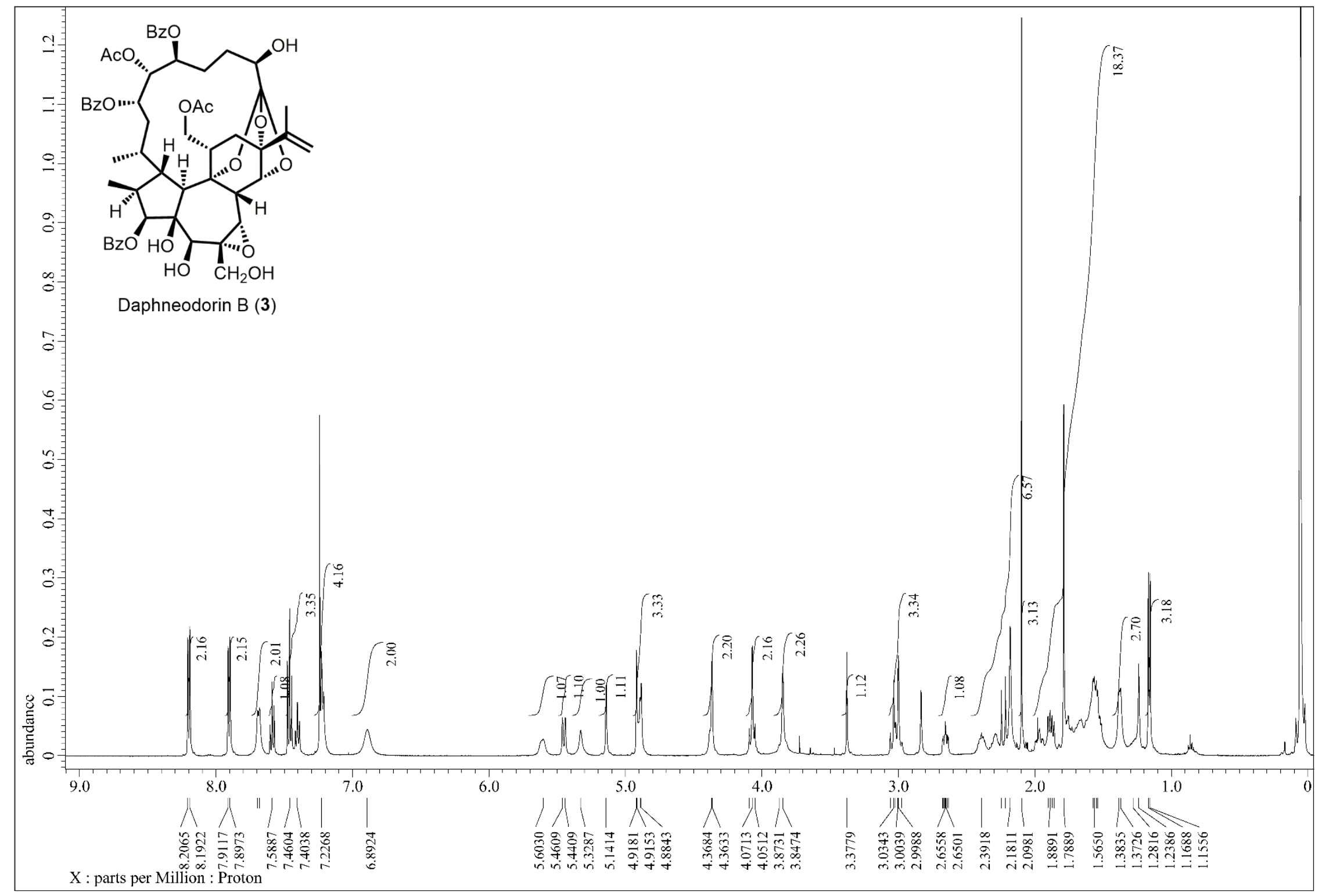

Figure S12. The ${ }^{1} \mathrm{H}-\mathrm{NMR}$ Spectrum of Compound 3 . 


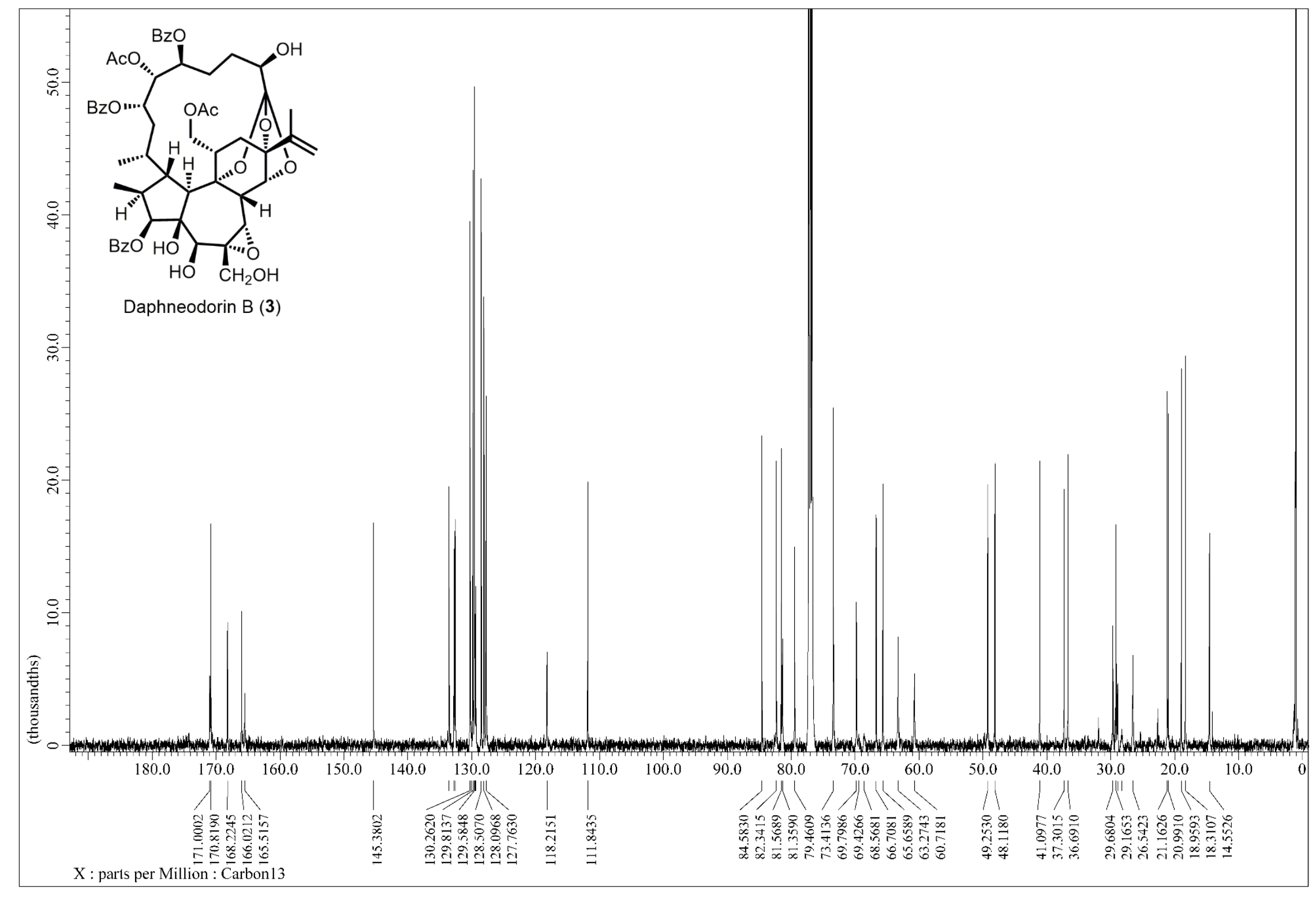

Figure S13. The ${ }^{13} \mathrm{C}-\mathrm{NMR}$ Spectrum of Compound 3. 


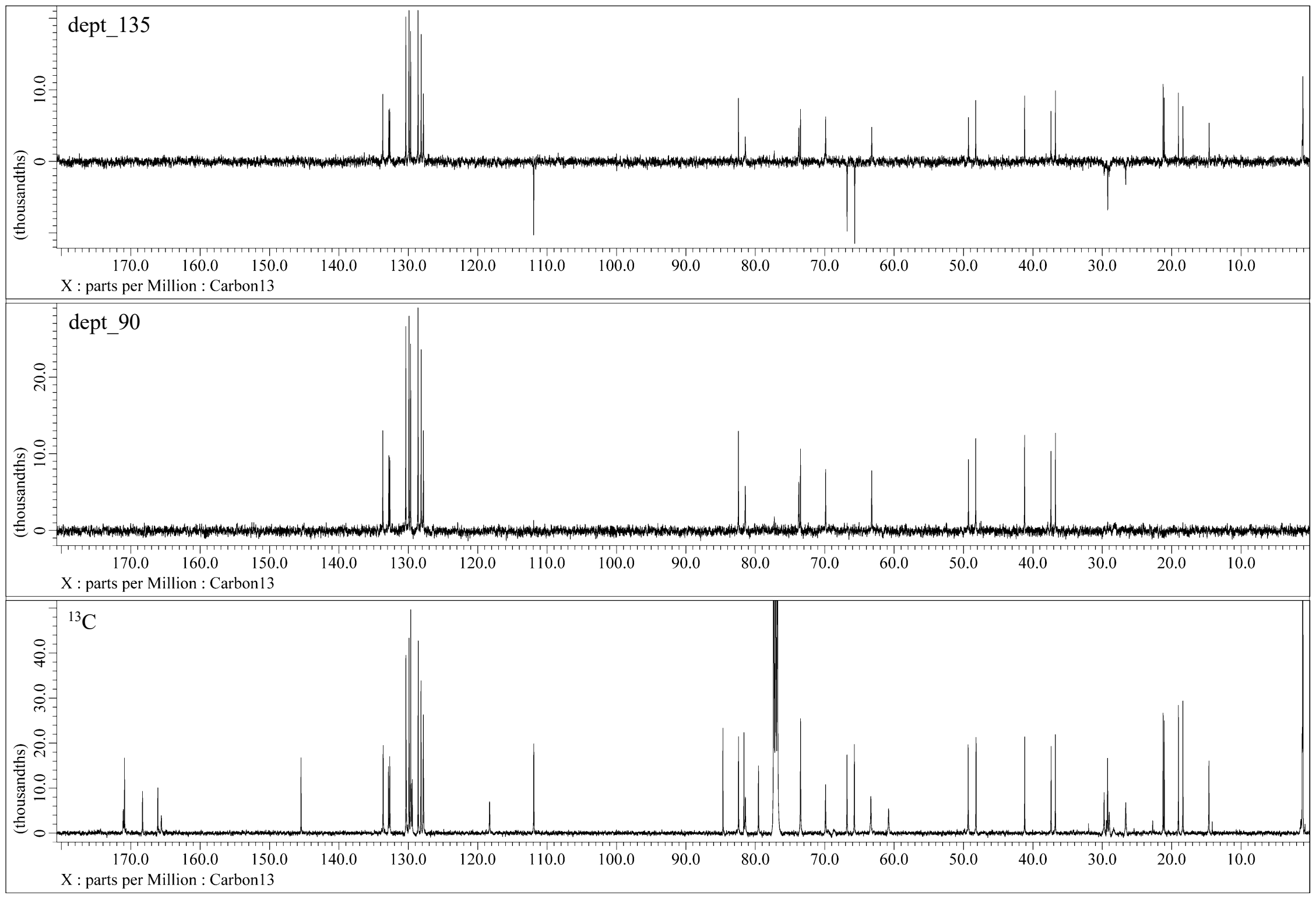

Figure S14. The DEPT Spectrum of Compound 3. 


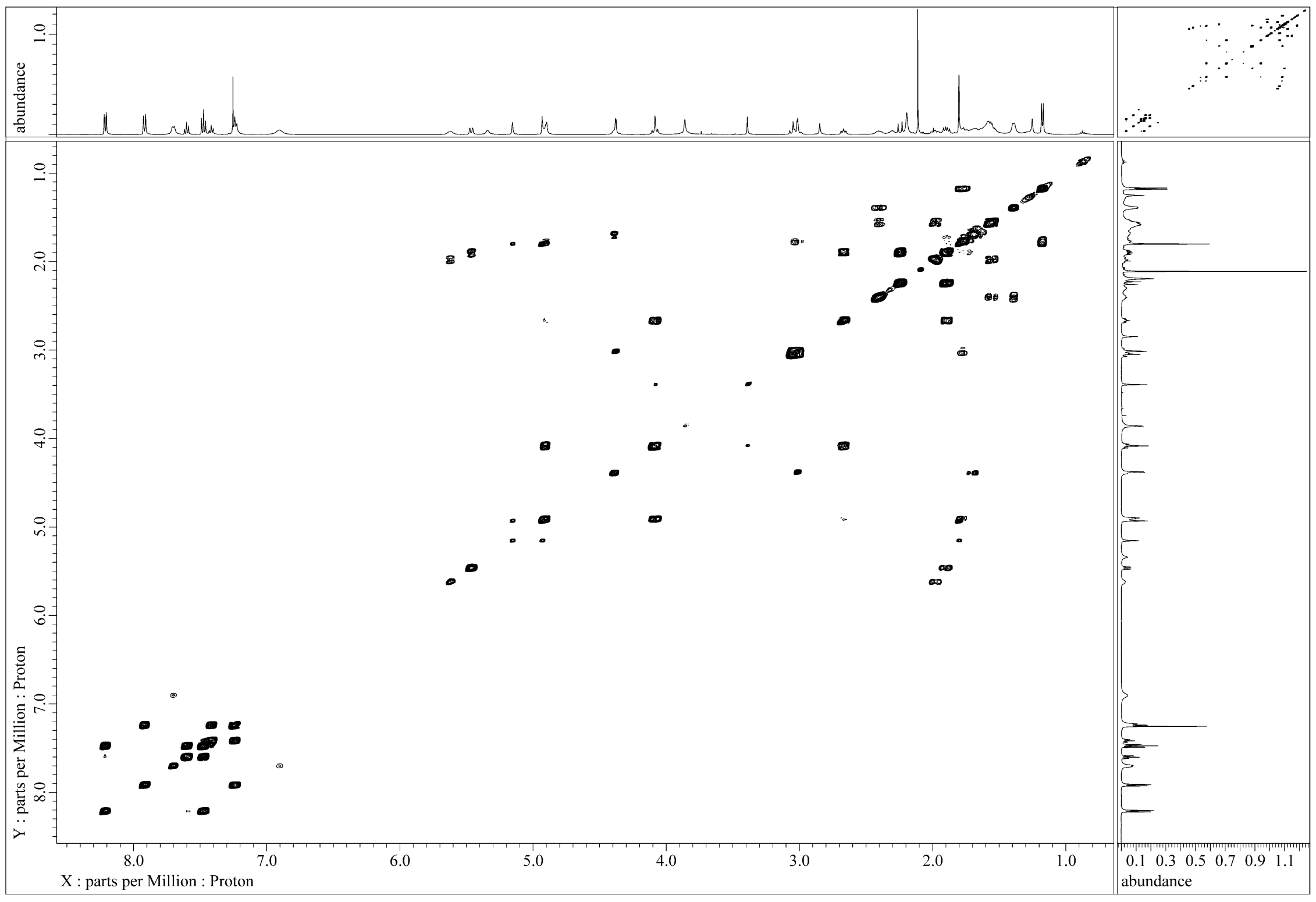

Figure S15. The DQF-COSY Spectrum of Compound 3. 


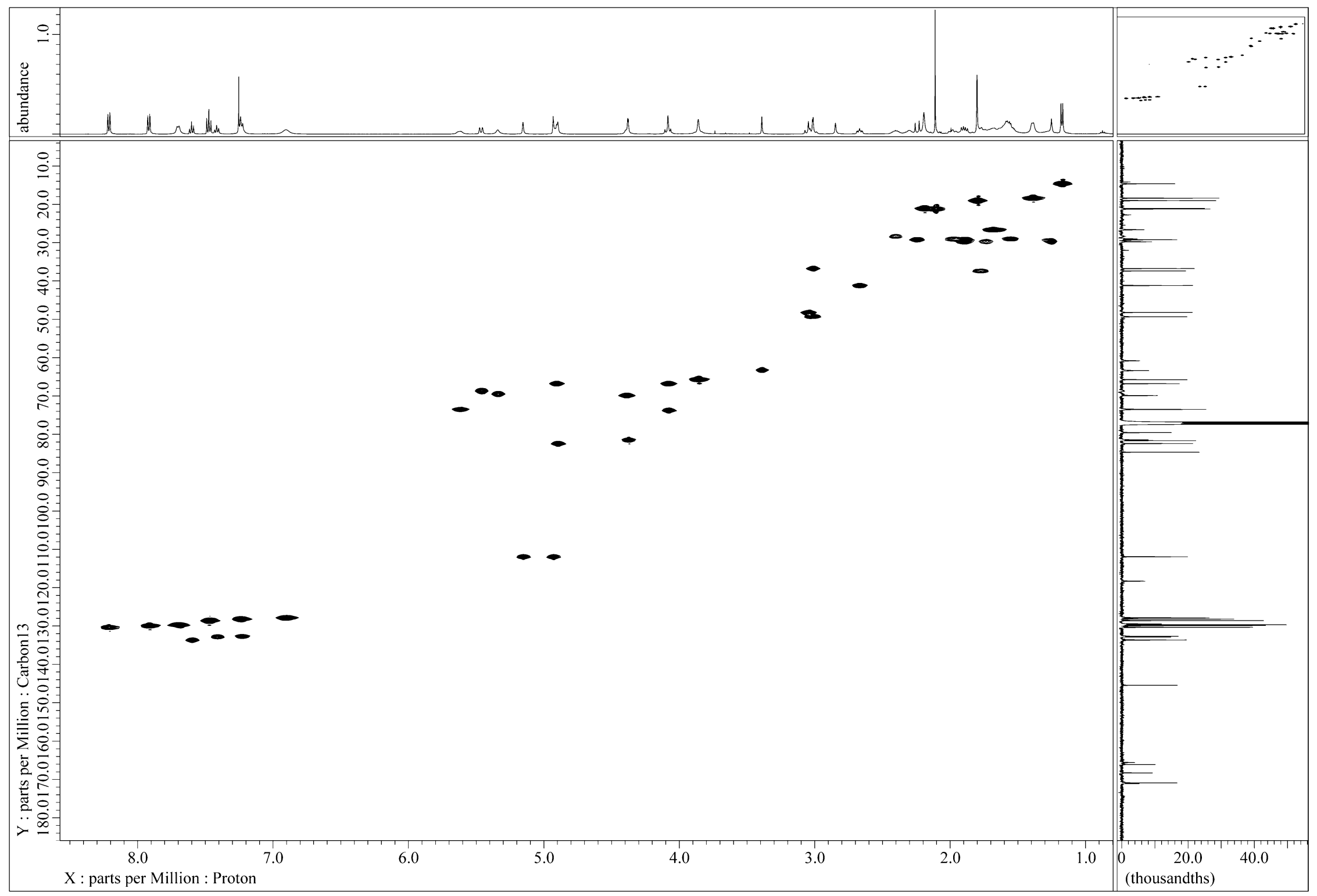

Figure S16. The HSQC Spectrum of Compound 3.

S 20 


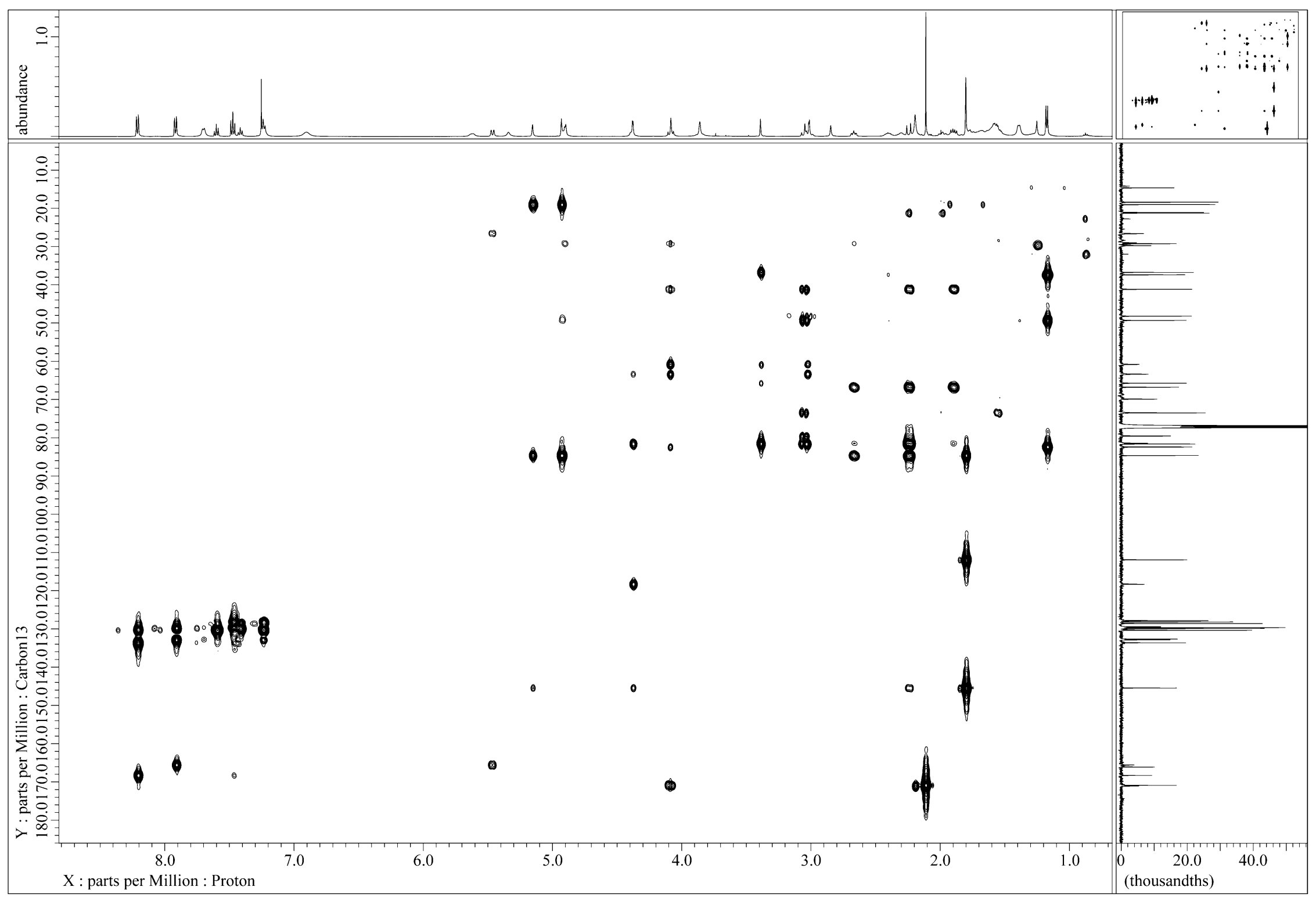

Figure S17. The HMBC Spectrum of Compound 3. 


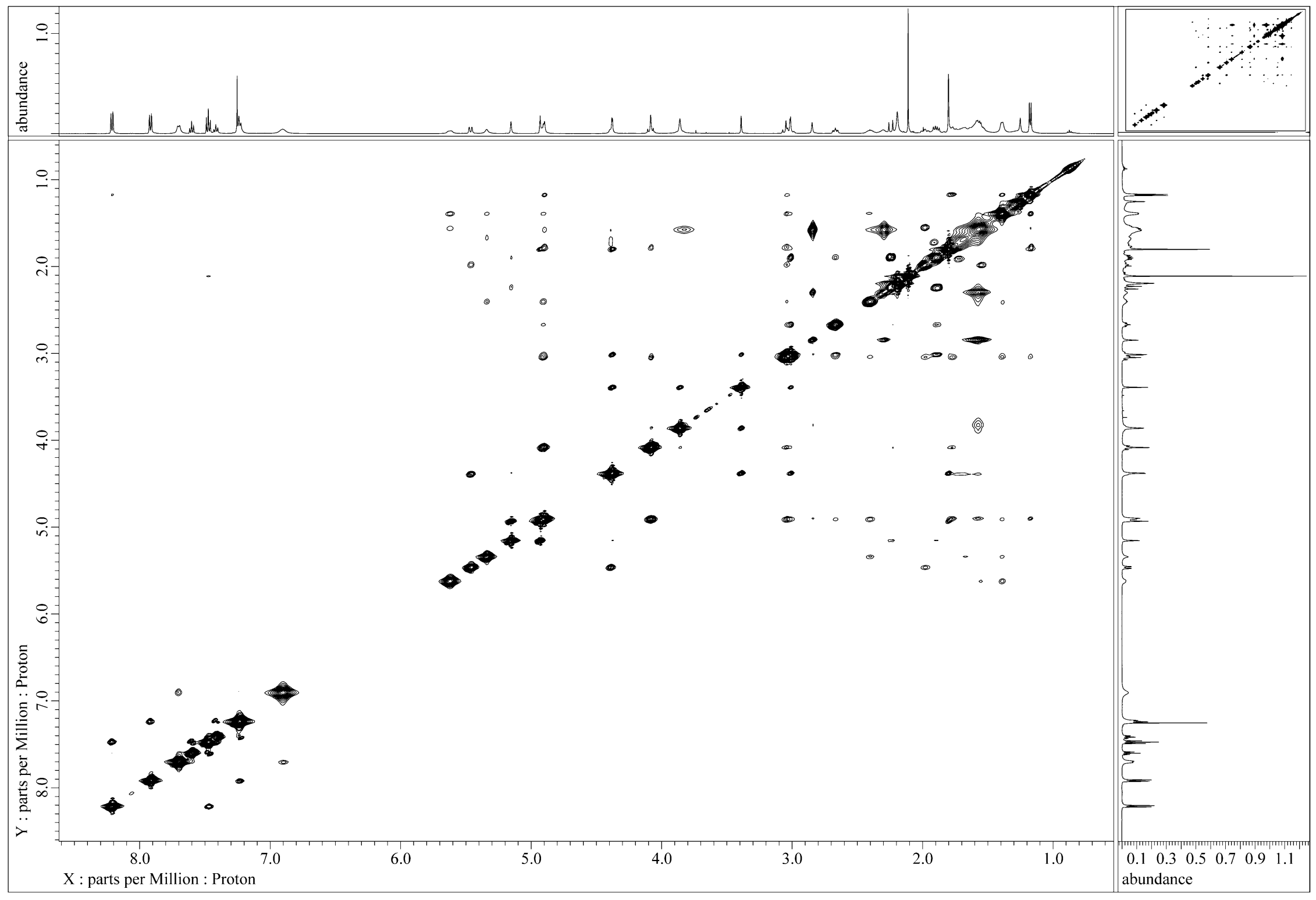

Figure S18. The NOESY Spectrum of Compound 3. 
データ:DOSO-E_181117

試料名:

説明:

イオン化モード:ESI+

処理履歴: $\mathrm{m} / \mathrm{z}$ 軸決定[ピーク検出[重心,30,面積];ベース補正[5.0\%];平滑化[3]];ベース補正[5.0\%];平均(MS[1] 0.25..0.36)

電荷数: 1

元素: ${ }^{12} \mathrm{C}: 0 . .100,{ }^{1} \mathrm{H}: 0 . .200,{ }^{23} \mathrm{Na}: 1 . .1,{ }^{16} \mathrm{O}: 0$.. 20

\begin{tabular}{|c|l|r|r|r|r|r|r|}
\hline 質量 & 強度 & 相対強度 & 計算質量 & $\begin{array}{c}\text { 質量差 } \\
\mathrm{mmu}\end{array}$ & $\begin{array}{c}\text { 質量差 } \\
\mathrm{ppm}\end{array}$ & $\begin{array}{c}\text { 推定組成式 } \\
\text { 年飽和数 }\end{array}$ \\
\hline \hline 1033.38392 & 50371.93 & 100.00 & 1033.38338 & 0.54 & 0.52 & ${ }^{12} \mathrm{C}_{55}{ }^{1} \mathrm{H}_{62}{ }^{23} \mathrm{Na}^{16} \mathrm{O}_{18}$ & 24.5 \\
\hline
\end{tabular}

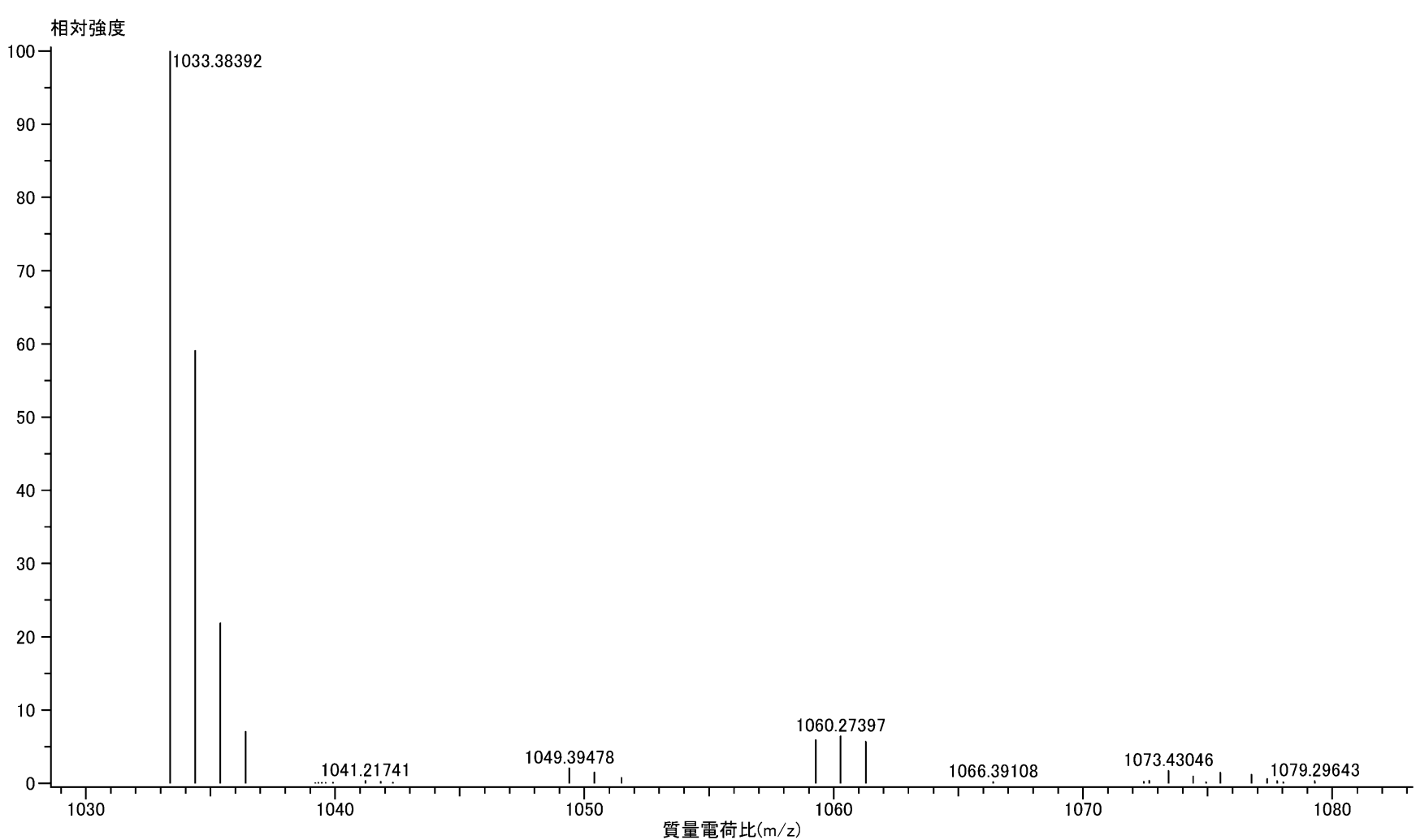

Figure S19. The HR-ESI-MS Spectrum of Compound 3. 


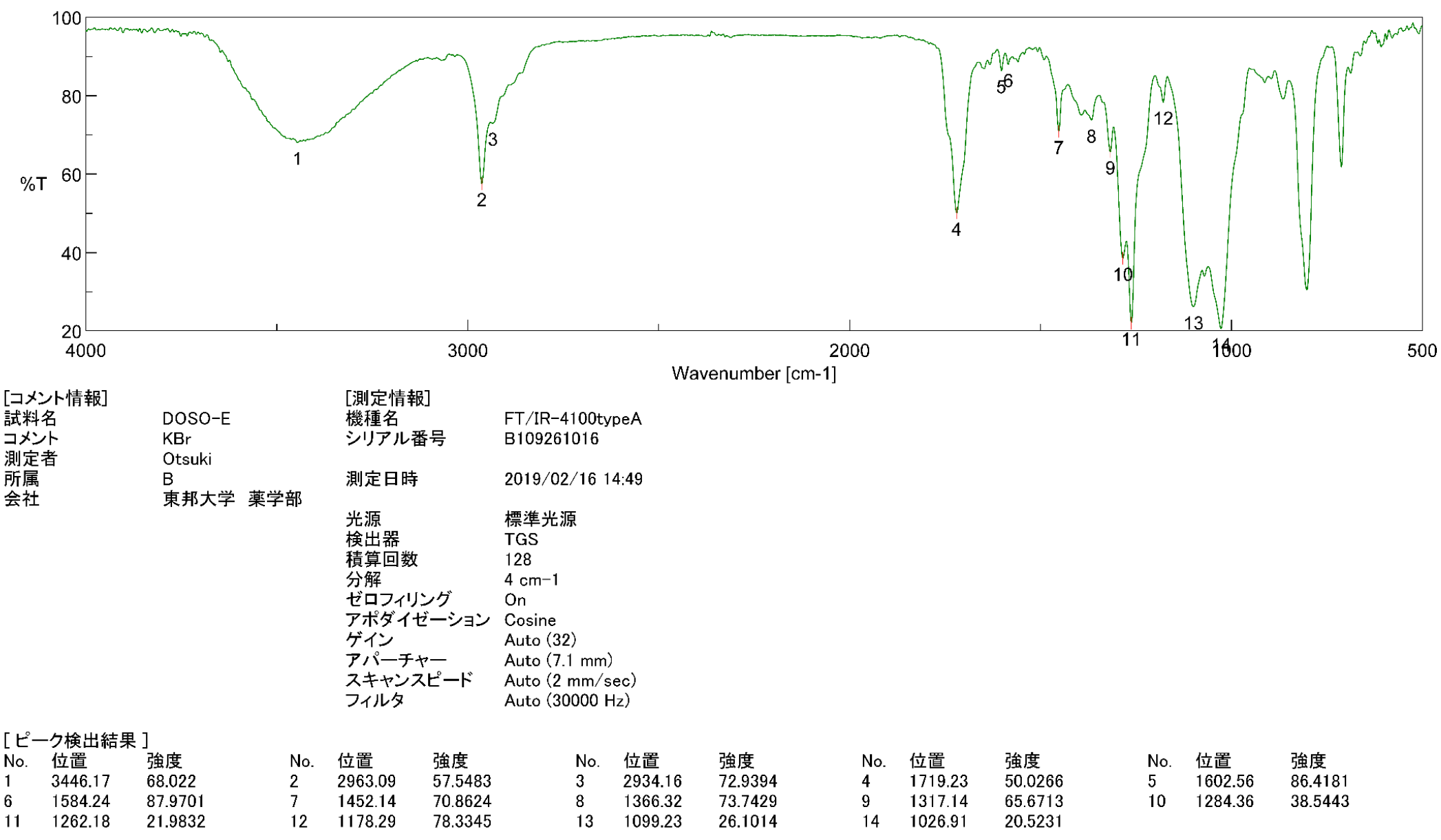

Figure S20. The IR Spectrum of Compound 3. 


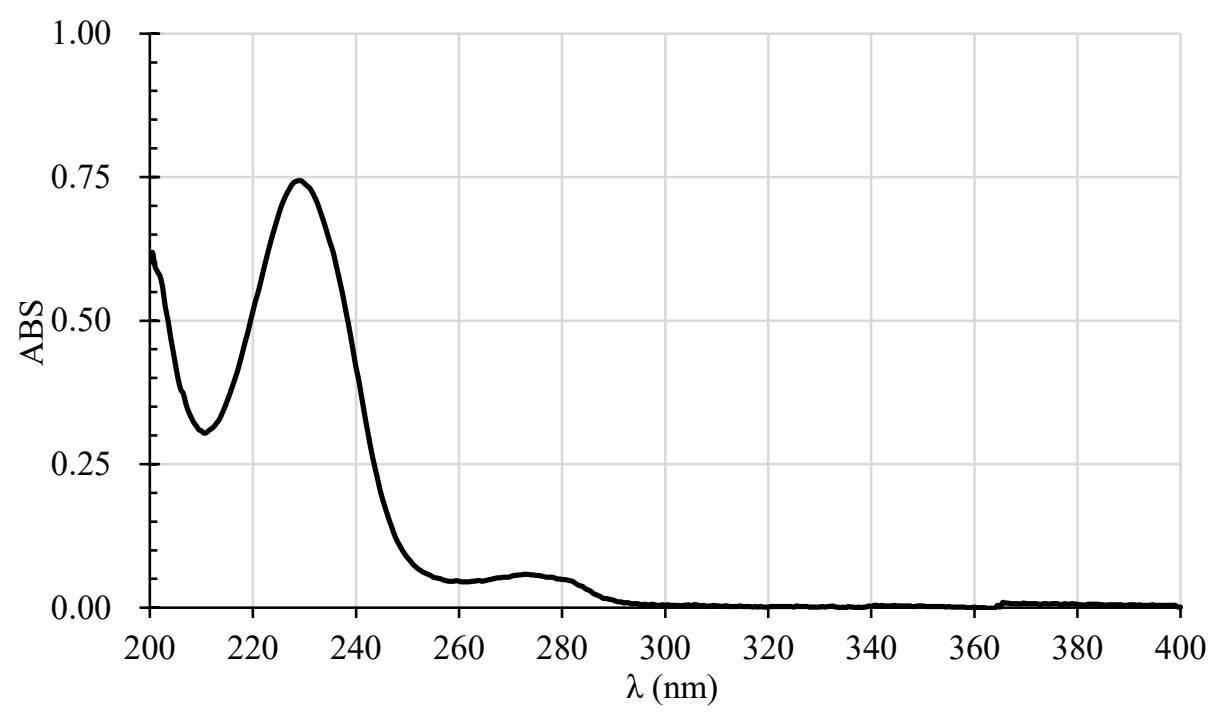

Figure S21. The UV Spectrum of Compound 3.

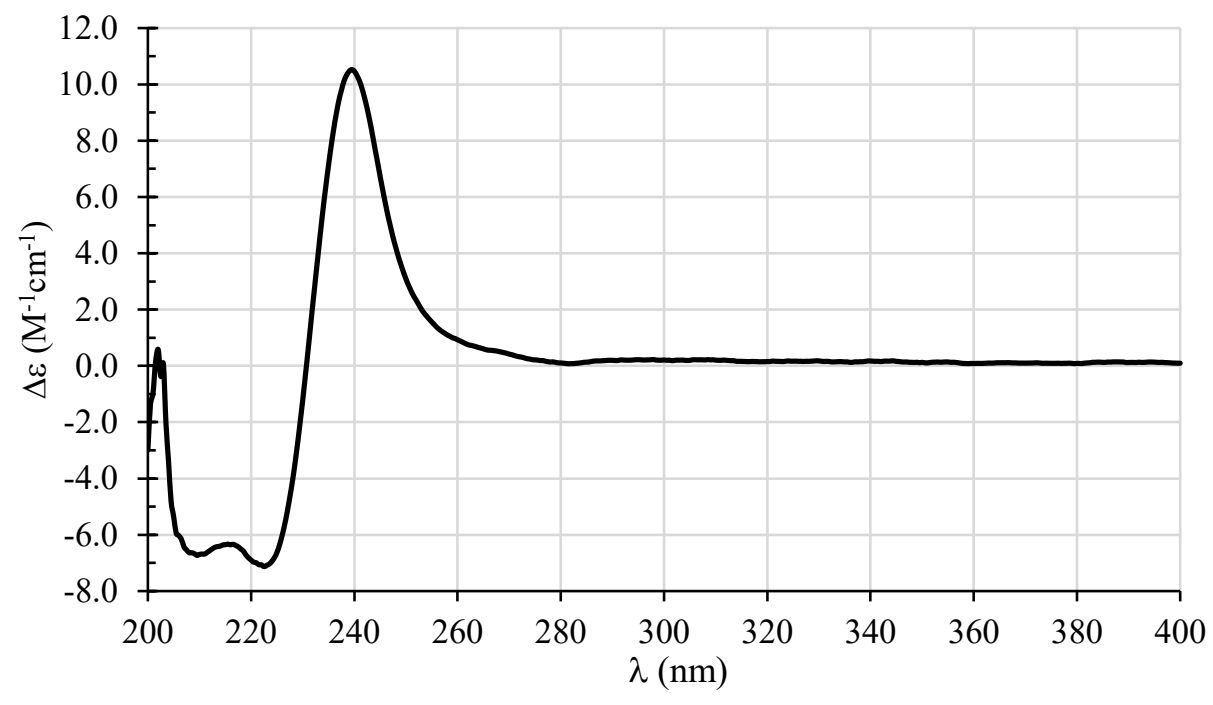

Figure S22. The ECD Spectrum of Compound 3. 


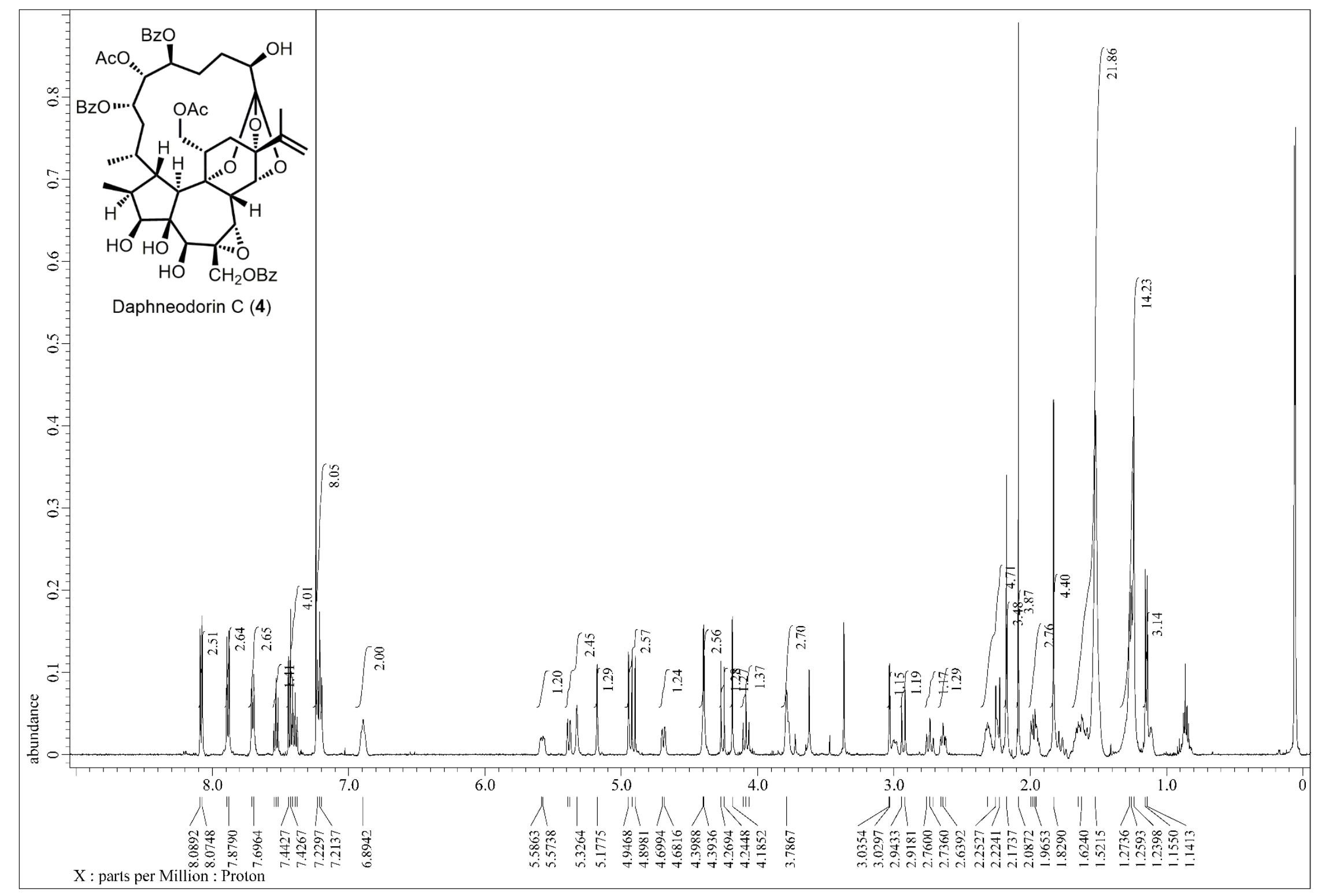

Figure S23. The ${ }^{1} \mathrm{H}-\mathrm{NMR}$ Spectrum of Compound 4. 


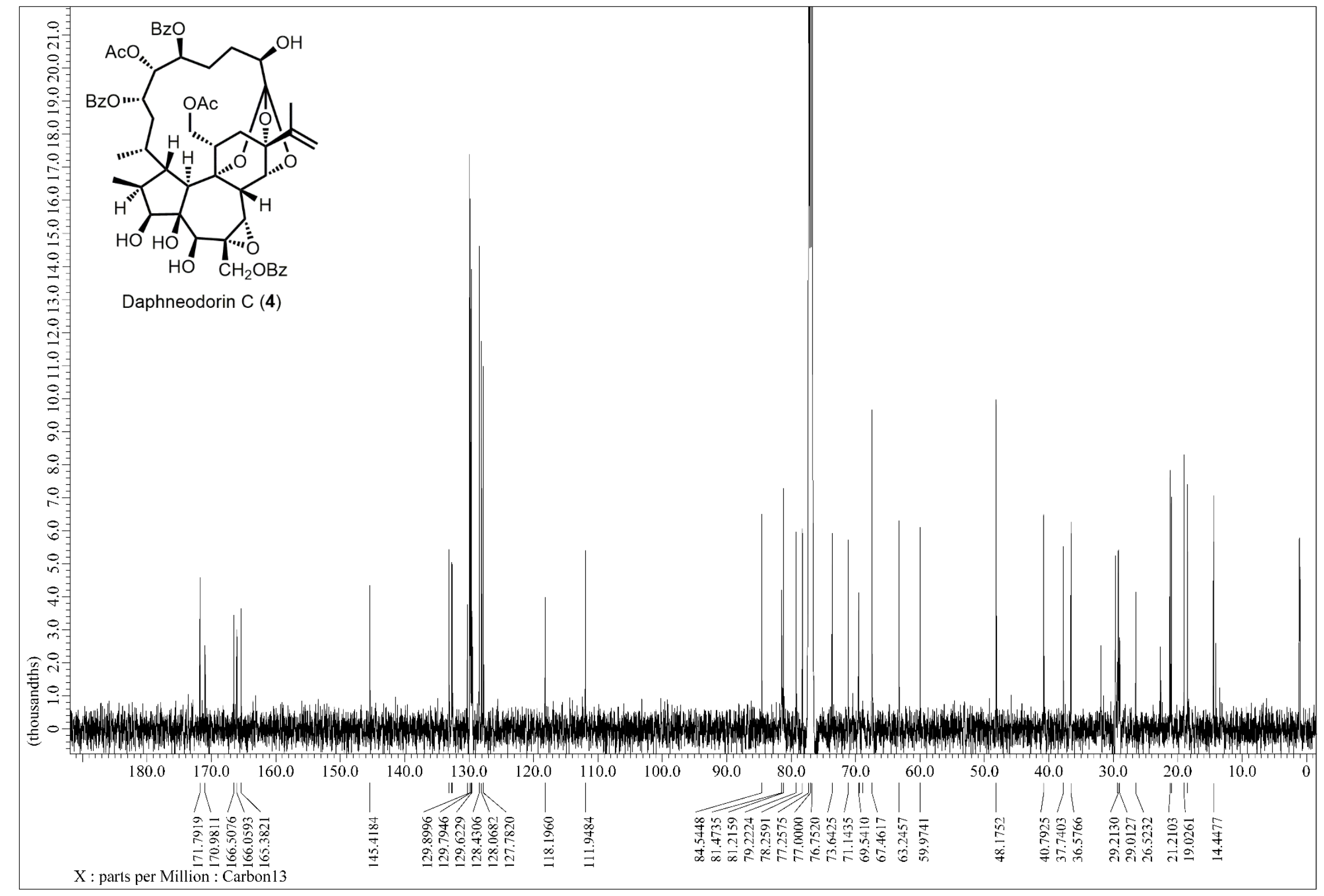

Figure S24. The ${ }^{13}$ C-NMR Spectrum of Compound 4. 


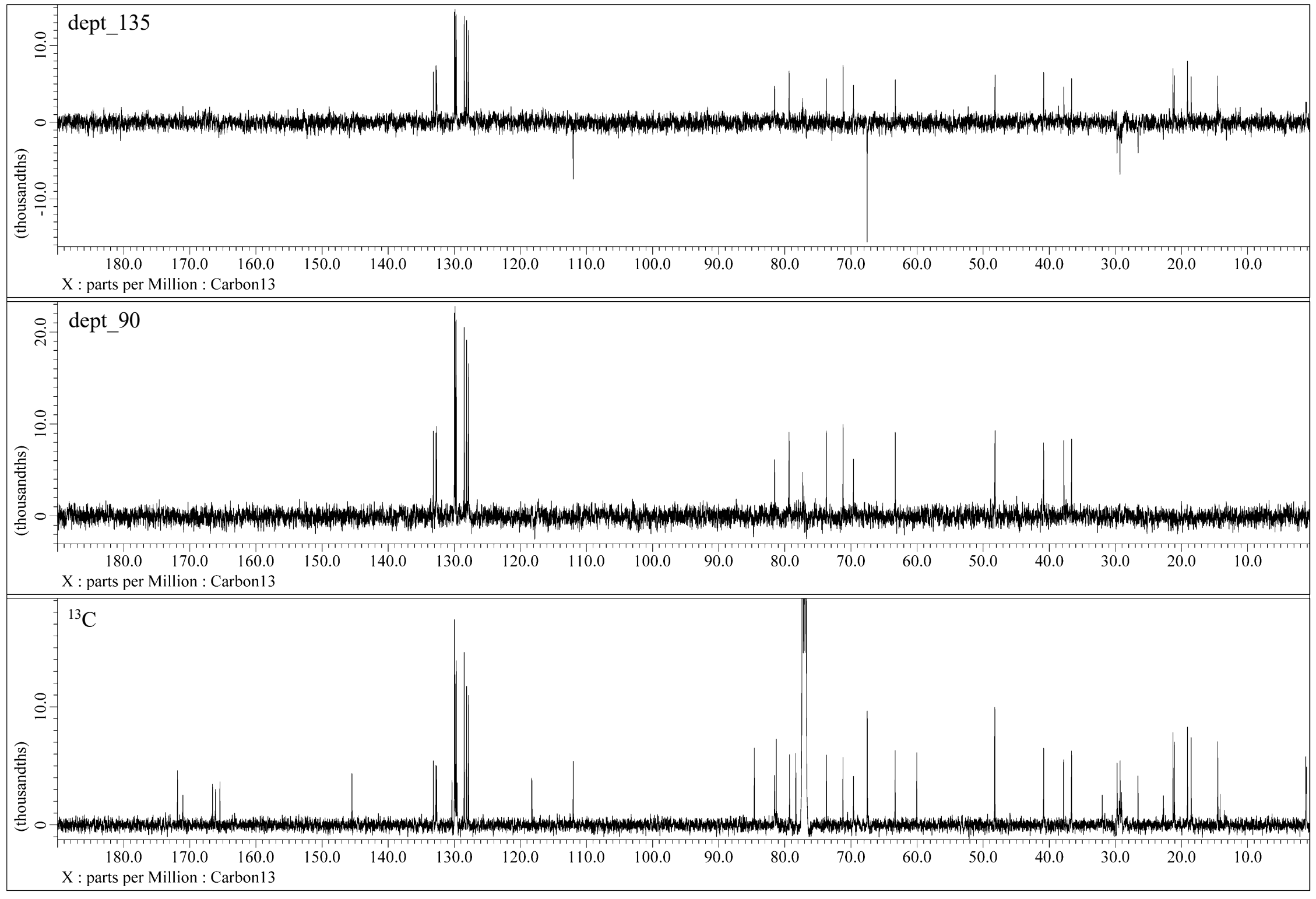

Figure S25. The DEPT Spectrum of Compound 4. 


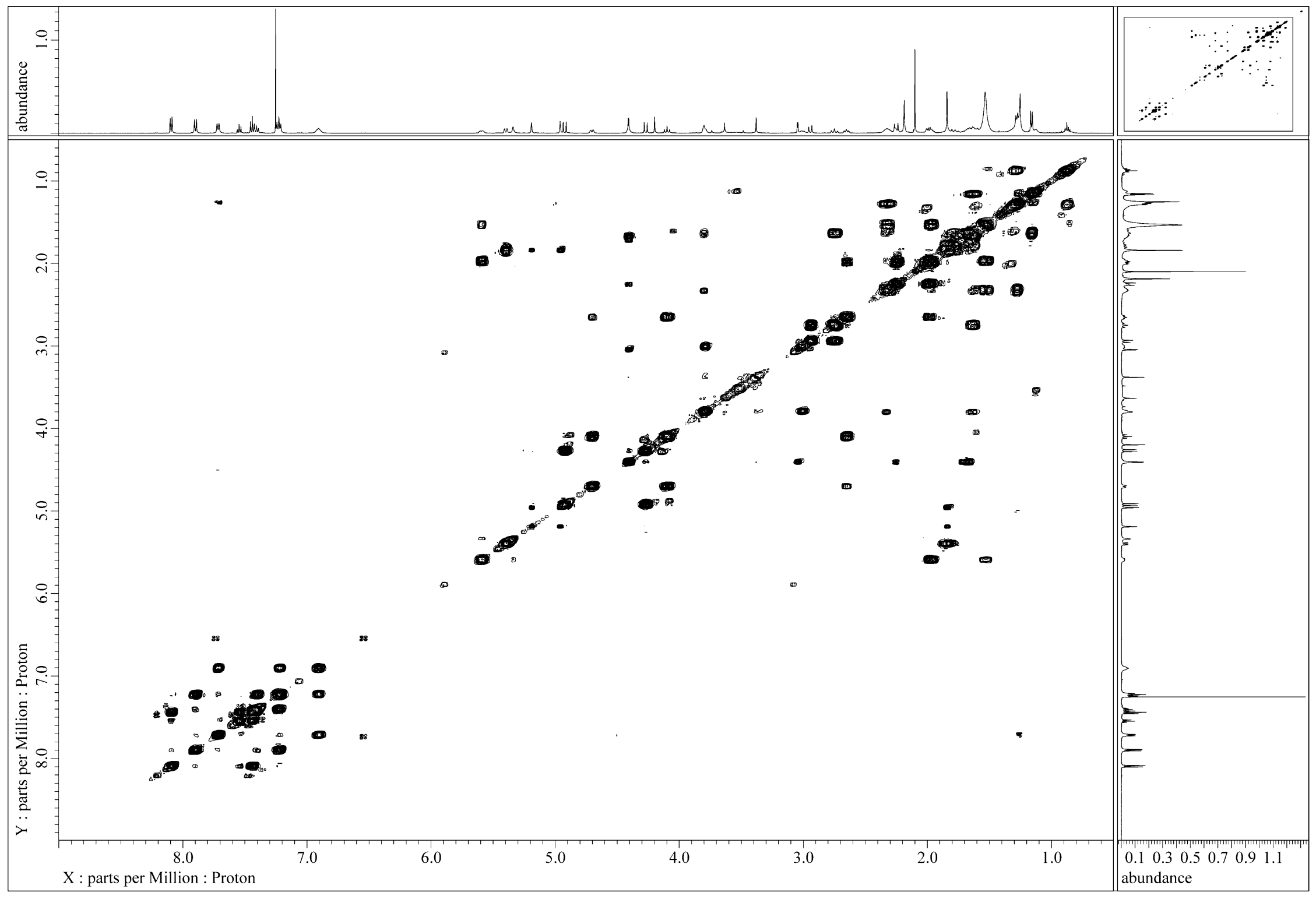

Figure S26. The DQF-COSY Spectrum of Compound 4. 


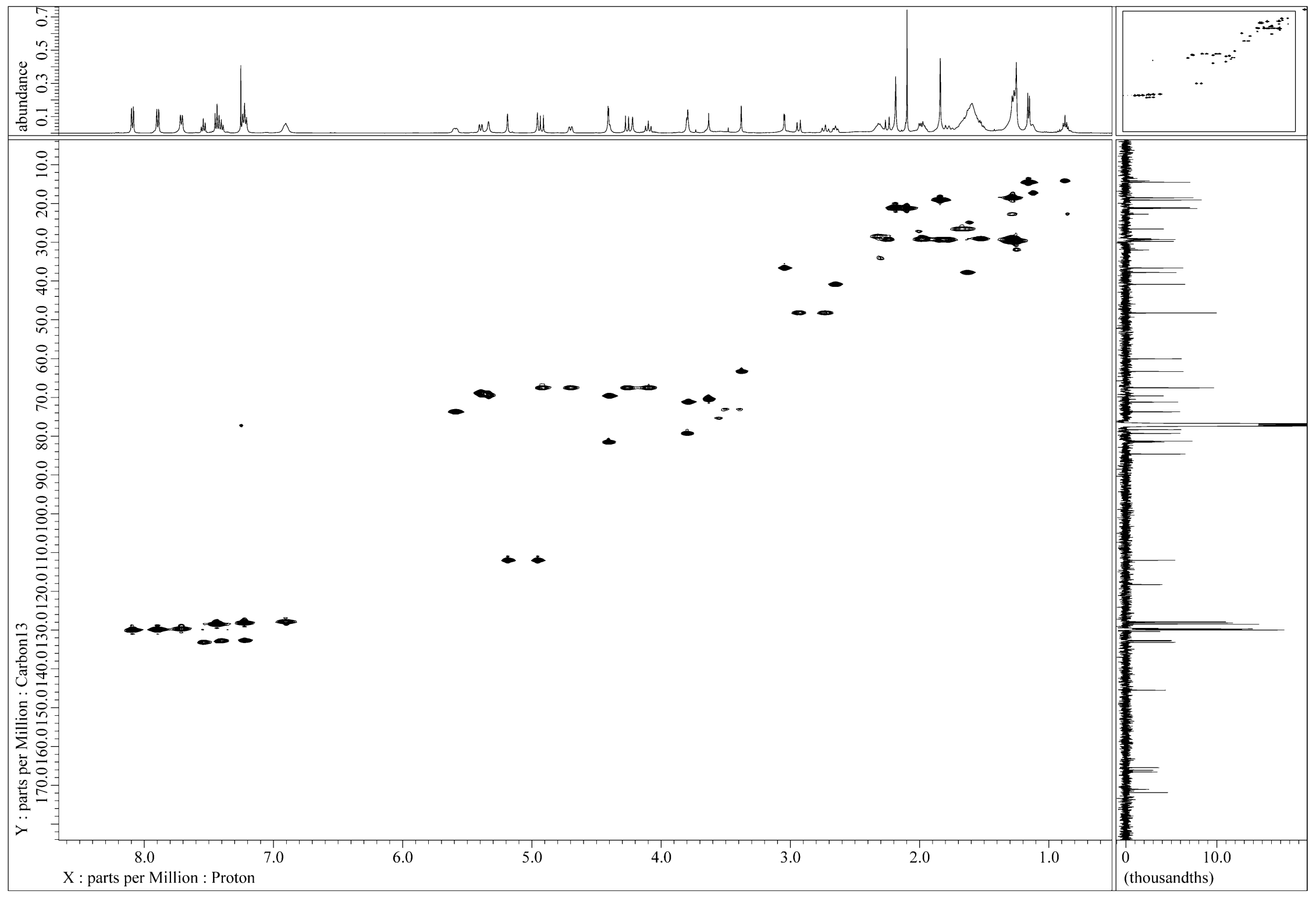

Figure S27. The HSQC Spectrum of Compound 4. 


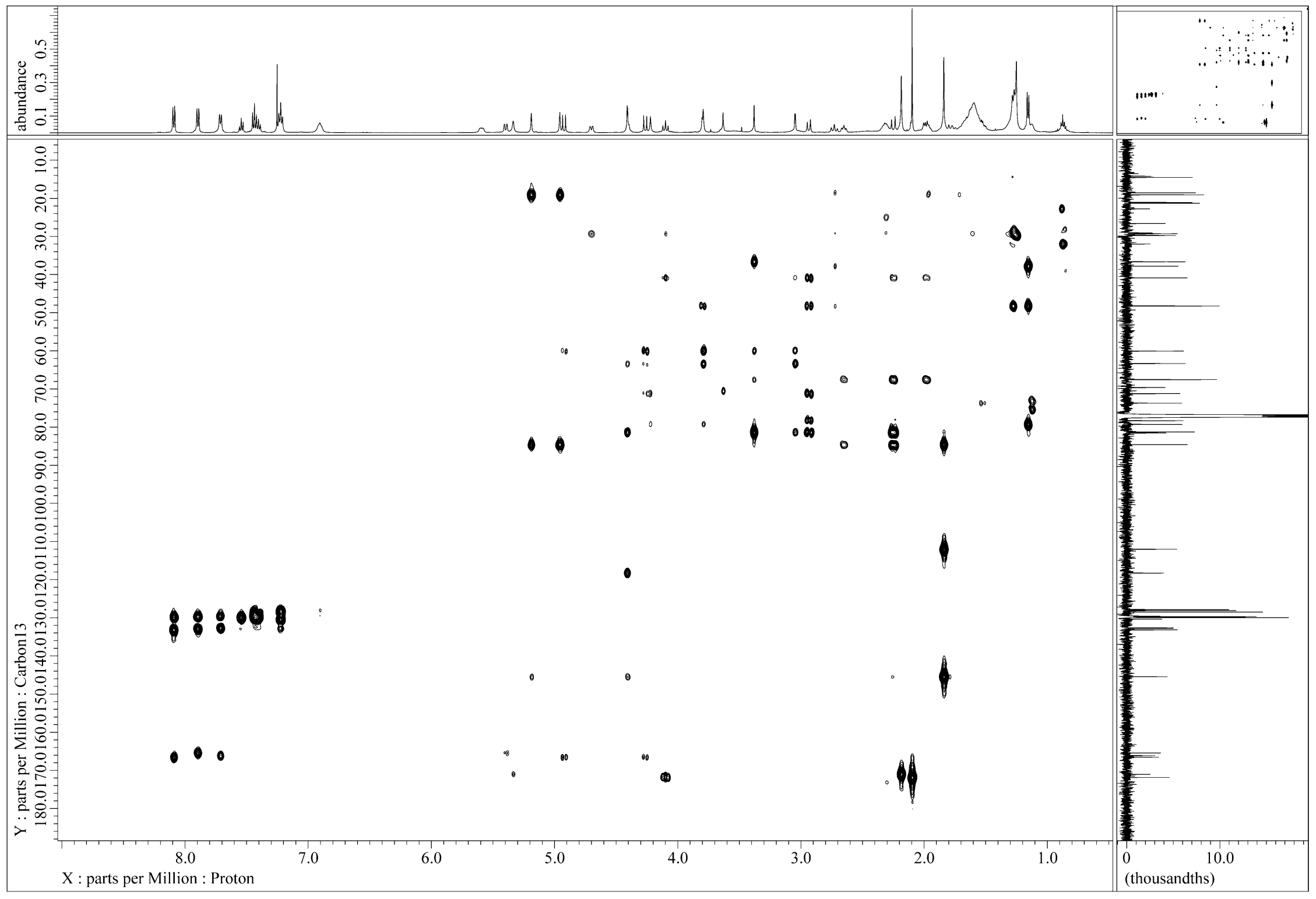

Figure S28. The HMBC Spectrum of Compound 4. 


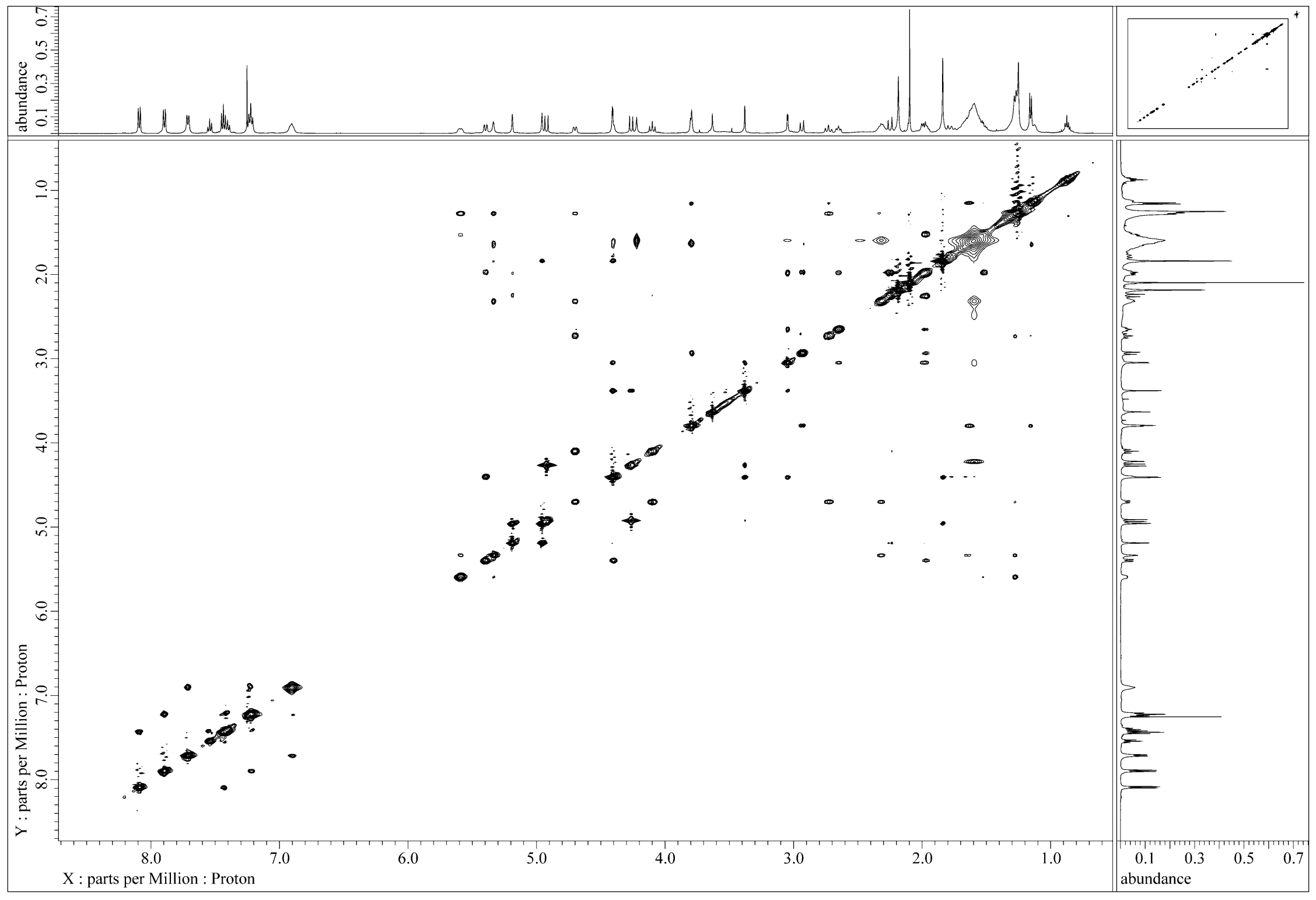

Figure S29. The NOESY Spectrum of Compound 4. 
データ:DOL-E2 181117

試料名:

説明:

イオン化モード:ESI+

処理履歴: $\mathrm{m} / \mathrm{z}$ 軸決定[ピーク検出[重心,30,面積];ベース補正[5.0\%];平滑化[3]];ベース補正[5.0\%];平均(MS[1] 0.32..0.35)

電荷数: 1

元素: ${ }^{12} \mathrm{C}: 0 . .100,{ }^{1} \mathrm{H}: 0 . .200,{ }^{23} \mathrm{Na}: 1 . .1,{ }^{16} \mathrm{O}: 0 . .20$

\begin{tabular}{|c|c|r|c|r|r|r|r|} 
質量 & 強度 & 相対強度 & 計算質量 & $\begin{array}{c}\text { 質量差 } \\
\mathrm{mmu}\end{array}$ & $\begin{array}{c}\text { 質量差 } \\
\mathrm{ppm}\end{array}$ & $\begin{array}{c}\text { 推定組成式 } \\
\text { 不飽和数 }\end{array}$ \\
\hline \hline 1033.38434 & 86301.81 & 100.00 & 1033.38338 & 0.96 & 0.93 & ${ }^{12} \mathrm{C}_{55}{ }^{1} \mathrm{H}_{62}{ }^{2}{ }^{2} \mathrm{Na}_{1}{ }^{16} \mathrm{O}_{18}$ & 24.5 \\
\hline
\end{tabular}

相対強度

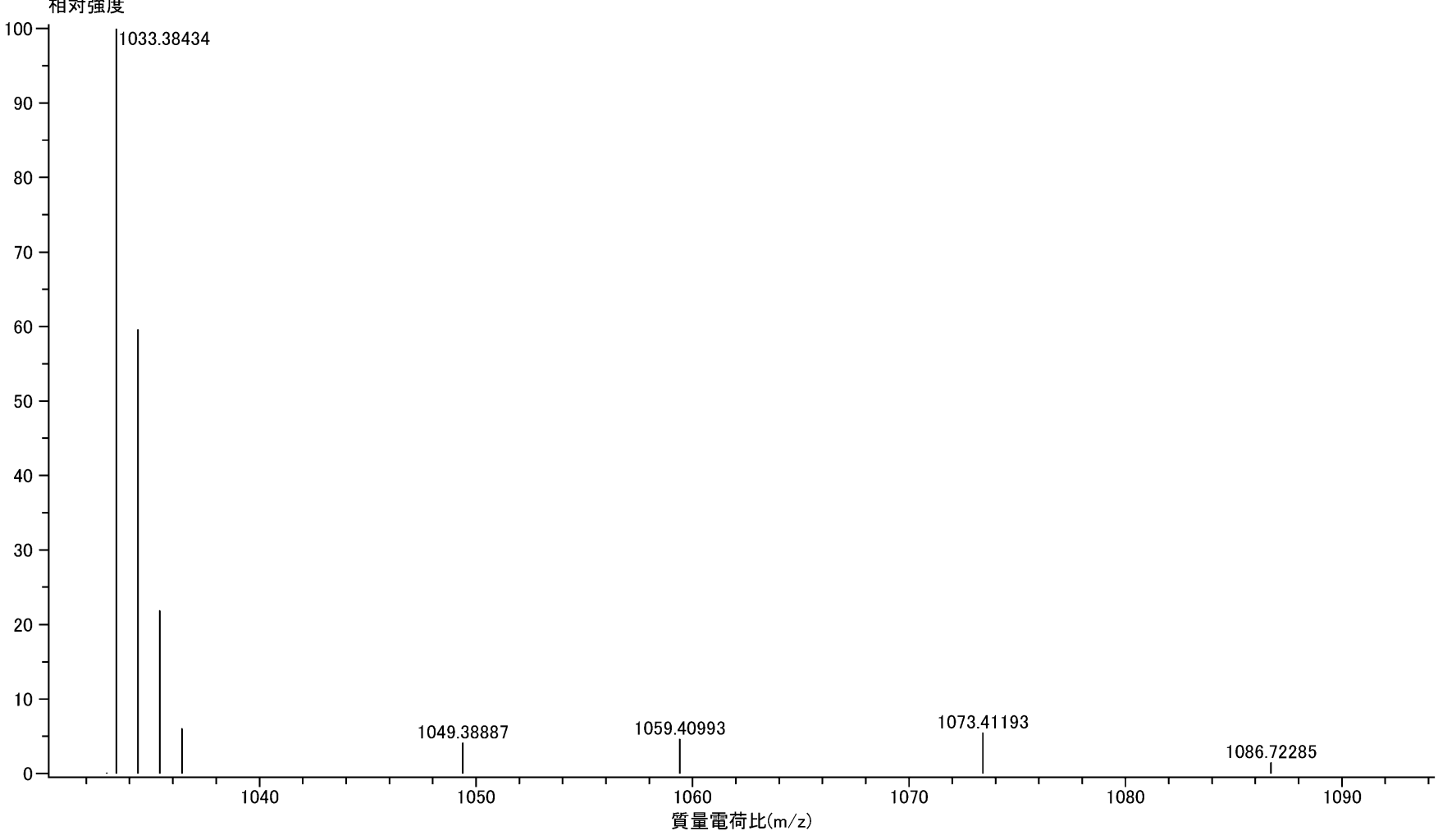

Figure S30. The HR-ESI-MS Spectrum of Compound 4.
測定日時: 2018/11/17 12:53:33 測定者: Administrator

質量校正データ: $190627+$

作成日時: 2019/06/27 19:13:02

作成者: Administrator

不飽和数: $-1.5 \ldots 30.0$ (端数:両方)
許容誤差: $5.00(\mathrm{ppm}), 5.00$.. 15.00(mmu) 


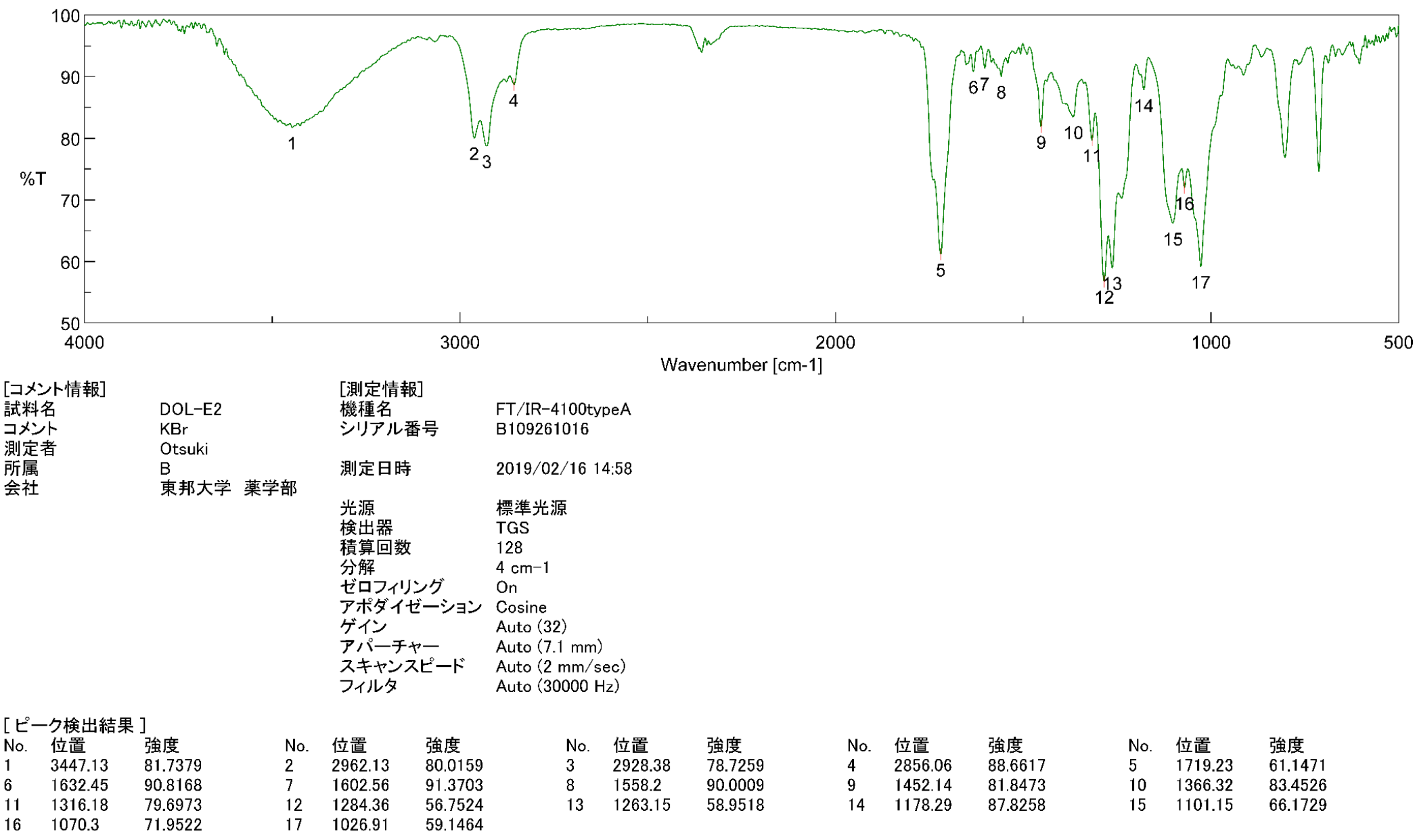

Figure S31. The IR Spectrum of Compound 4. 


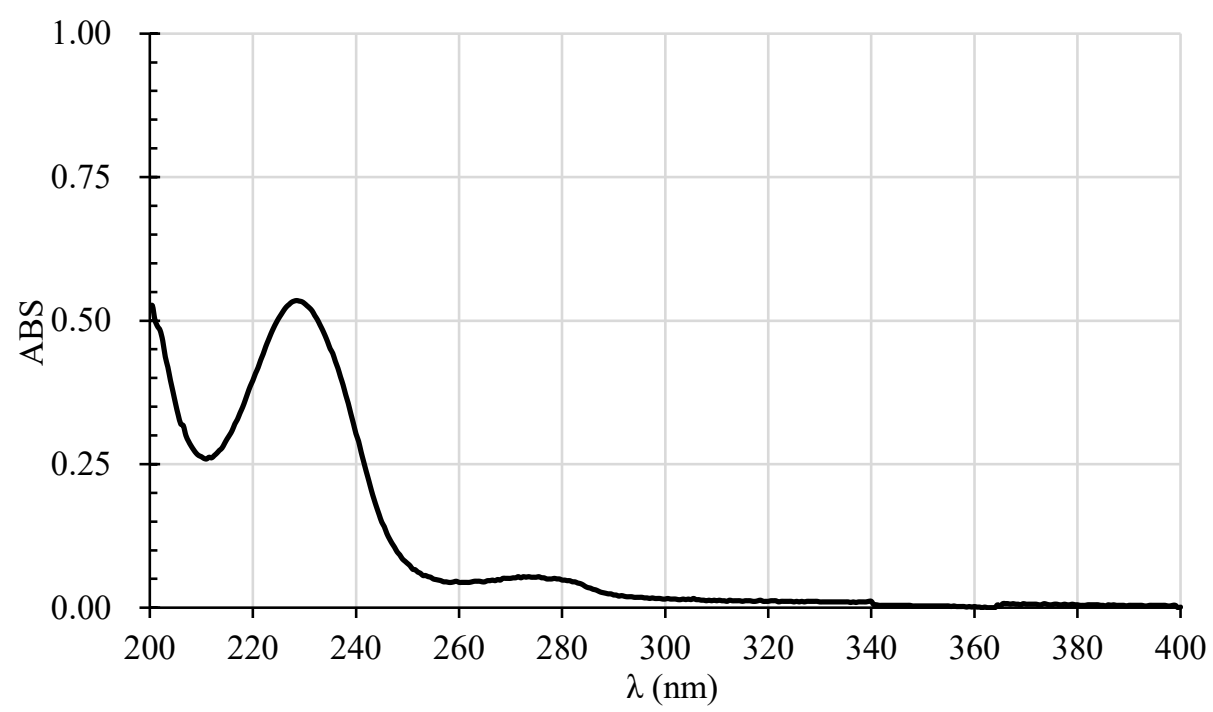

Figure S32. The UV Spectrum of Compound 4.

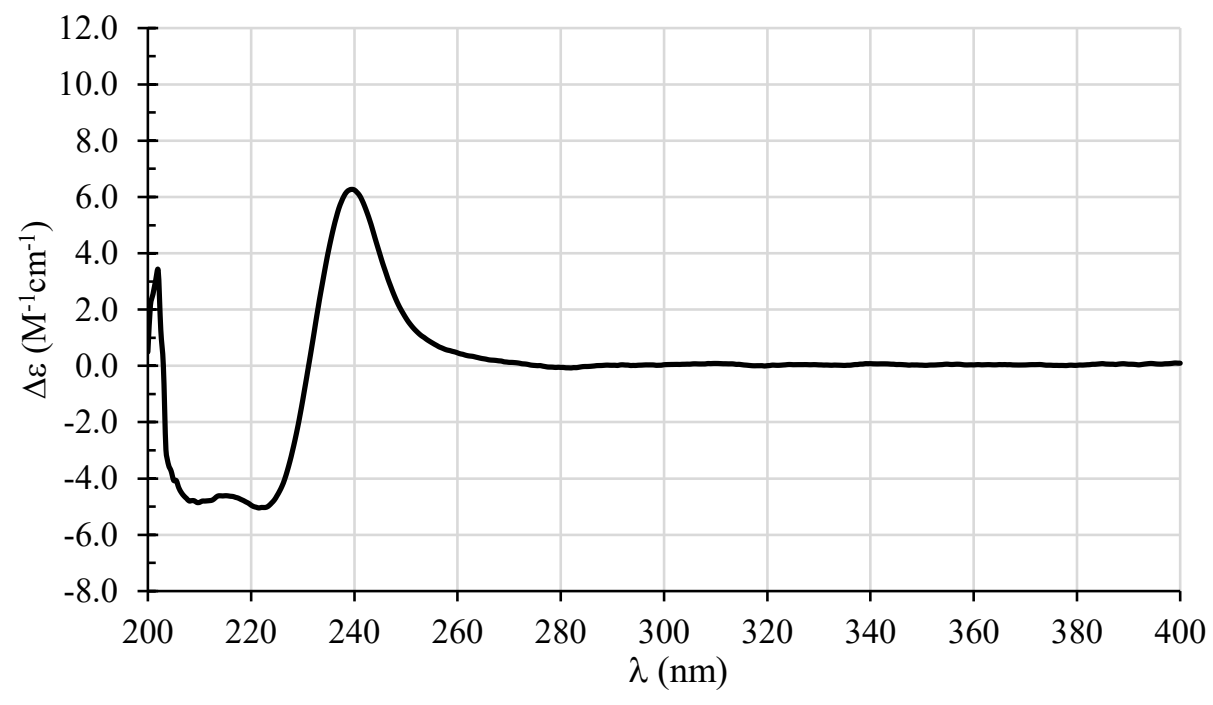

Figure S33. The ECD Spectrum of Compound 4. 